\title{
LA SALIDA INTEMPESTIVA Y LA NEGATIVA A TRABAJAR: UN SUPUESTO DE ABANDONO POR INCUMPLIMIENTO CONTRACTUAL
}

\author{
THE UNTIMELY LEAVING AND THE REFUSAL TO WORK: AN \\ ASSUMPTION OF ABSENTEEISM DUE TO BREACH OF CONTRACT
}

\section{Pedro Irureta Uriarte*}

\begin{abstract}
RESUMEN: El Código del Trabajo sanciona un caso especial de abandono por incumplimiento contractual. Dicho incumplimiento se verifica por la salida intempestiva del puesto de trabajo y por la negativa a ejecutar las labores convenidas en el contrato. En ambos casos, el Código circunscribe la infracción en torno a requisitos fundados en la contractualidad de la desobediencia y en la falta de justificación de la misma. Si bien se trata de un antiguo supuesto de extinción del contrato, la figura ha servido para diferenciar los supuestos de abandono por incumplimiento de aquellos que suponen una renuncia al empleo. Asimismo, la evolución jurisprudencial ha permitido superar la vieja doctrina del solve et repete por una mirada más amplia de la desobediencia justa.
\end{abstract}

Palabras clave: Abandono del trabajo, incumplimiento contractual, despido disciplinario.

ABSTRACT: The Labor Code penalizes a special case of absenteeism caused by breach of contract. This is verified by the untimely leaving of an employee from his or her workplace and the refusal to execute the tasks agreed upon in the employment contract. In both cases, the Code circumscribes the infraction around requirements based on contractual terms about disobedience and in its lack of justification. Even though this is about an old assumption on extinction of contract, the figure has served to differentiate the assumptions of absenteeism due to breach of contract from those that suppose quitting a job. Also, the jurisprudential evolution has allowed the replacement of the old doctrine of solve et repete by a wider view of just disobedience.

Key words: Laboral absenteeism, breach of contract, disciplinary dismissal.

\footnotetext{
Abogado y Licenciado en Derecho por la Pontificia Universidad Católica de Chile. Doctor en Derecho por la Universidad Complutense de Madrid, Profesor Titular de Derecho del Trabajo de la Universidad Alberto Hurtado. Dirección postal: Almirante Barroso 10, Santiago. Correo electrónico: piruret@uahurtado.cl El presente trabajo se inscribe dentro del proyecto de investigación Fondecyt $\mathrm{N}^{\circ} 1140993$, denominado "La configuración de los elementos centrales de las causas disciplinarias de extinción del contrato de trabajo", ejecutado por el autor en calidad de investigador responsable.

Abreviaturas: AL (Actualidad Laboral); CAP (Corte de Apelaciones); CPR (Constitución Política de la República); CS (Corte Suprema); CT (Código del Trabajo); GJ (Gaceta Jurídica); RDJ (Revista de Derecho y Jurisprudencia y Gaceta de los Tribunales); RDP (Revista de Derecho Privado); Revista Española de Derecho del Trabajo (REDT); RFD (Revista de la Facultad de Derecho de la Universidad de Madrid); RFM (Revista Fallos del Mes); RPS (Revista de Política Social); RL (Relaciones Laborales); RT (Revista de Trabajo); TS (Tribuna Social); SEC (Sección); T (Tomo).
} 


\section{INTRODUCCIÓN}

En todo contrato de trabajo subyace un deber mínimo exigible al trabajador, consistente en prestar servicios y ponerse a disposición del empleador. Así se desprende, entre otras, de las normas establecidas en el artículo $3^{\circ}$, letra b), y $7^{\circ}$ del Código del Trabajo, las cuales ponen el acento en la obligación que asume el trabajador de prestar servicios en un régimen de subordinación o dependencia. Esta cualidad de la prestación de servicios explica en parte importante la existencia de un poder de dirección del empleador, cuyo fundamento último se encuentra en el propio artículo $19 \mathrm{~N}^{\circ} 16$ y $21 \mathrm{CPR}$.

El deber de ejecutar el trabajo comprometido se incumple cada vez que el deudor de la prestación abandona su puesto de trabajo o se niega a ejecutar las labores convenidas, sin causa justificada ${ }^{1}$. A fin de cuentas, la subordinación o dependencia que arguye el Código implica un deber preliminar del trabajador en el sentido de estar a disposición del empleador y ejecutar las labores convenidas.

La estructura del vínculo contractual presupone, también, que los servicios ejecutados por el trabajador se lleven a cabo de manera diligente; es decir, con el rendimiento propio o normal del buen trabajador ${ }^{2}$. Mediante esta diligencia se logra satisfacer el interés de la contraparte, y alcanzar un cumplimiento idóneo de acuerdo al iter contractual. De esta manera, hay ciertas conductas que afectan marcadamente la diligencia mínima que se espera en el cumplimiento de las obligaciones laborales. Y una de ellas es precisamente el abandono de las labores, por incumplimiento ${ }^{3}$.

En términos generales, todo abandono implica dejar un lugar o alejarse de él. En clave laboral, el abandono constituye un claro incumplimiento contractual que afecta la base misma sobre la cual se estructura el contrato de trabajo ${ }^{4}$. Si un trabajador deja su puesto de trabajo, o se aleja de él injustificadamente negándose a prestar servicios, entonces desatiende sus funciones, incumple el contenido obligacional del contrato y genera las consecuencias propias de una conducta contraria a la diligencia laboral.

Esta es la lógica que precisamente subyace en el Código del Trabajo. Dentro de las causas disciplinarias de despido podrá observarse como el legislador sanciona ciertas conductas de abandono bajo el razonamiento implícito que mediante ellas se afecta decididamente el iter contractual y el cumplimiento de las obligaciones más básicas que se esperan del trabajador.

\footnotetext{
1 Despax (1982) pp. 11 y ss. Véase también Ghera (2006) pp. 1 y ss.

2 Véase sentencia de la Corte de Apelaciones de Concepción de 6 de septiembre de 2002. GJ № 267 (2002) p. 191. Para un análisis general de esta temática, vid. además GarCía (1980) pp. 361 y ss; y SAGARDoY (1968) pp. 415 y ss.

${ }^{3}$ Doctrinariamente, se distingue entre el abandono como renuncia y el abandono como incumplimiento. En el primer caso, lo que se produce es una dejación voluntaria del empleo por parte del trabajador cuestión que en la práctica trae aparejada una especie de renuncia tácita. En el segundo caso, por el contrario, el abandono constituye una especial forma de incumplir el contrato ( $\mathrm{y}$ no de renunciar a él), generando de paso las consecuencias disciplinarias de que trata el Código del Trabajo. Sobre el particular, vid. por todos RojAS (2014) pp. 359 y ss.

4 Véase Thayer y Novoa (1998) p. 5 y González (1983) p. 34.
} 
Ciertamente, el Código ha regulado diversas infracciones vinculadas al abandono laboral. Así, por ejemplo, ha sancionado las inasistencias injustificadas, y la falta indebida o sin aviso de previo de quien tiene a su cargo una actividad, faena o máquina, "cuyo aban-

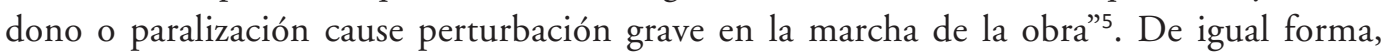
ha prohibido que alguna persona de la dotación de una nave pueda "dejar su empleo sin la intervención de la autoridad marítima o consular del puerto en que se encuentra la nave"6. Y por si esto no fuese suficiente, este mismo legislador ha establecido una hipótesis de clausura que permite sancionar cualquier incumplimiento grave de las obligaciones que impone el contrato, dentro de la cual también sería posible invocar supuestos de abandono ${ }^{7}$.

Sin embargo, en el propio Código del Trabajo existe una norma especial que se encarga de sancionar una hipótesis específica de abandono por incumplimiento, describiendo exactamente qué debe entenderse por esta clase de infracción. En efecto, el artículo 160 No 4 CT indica que el contrato de trabajo termina sin derecho a indemnización alguna cuando el empleador le ponga término fundado en el "abandono del trabajo por parte del trabajador, entendiéndose por tal: a) la salida intempestiva e injustificada del trabajador del sitio de la faena y durante las horas de trabajo, sin permiso del empleador o de quien lo represente, y b) la negativa a trabajar sin causa justificada en las faenas convenidas en el contrato". Ambas figuras tienen en común la idea de sancionar aquellas conductas que supongan dejar o desamparar el trabajo para el cual se ha contratado al trabajador. La configuración de este específico tipo de abandono es posible retrotraerlo a las primeras leyes sociales, ya que el artículo $5^{\circ} \mathrm{N}^{\circ} 11$ de la Ley $\mathrm{N}^{\circ} 4.053$, de 1924, sobre contrato del trabajo, establecía como causa de término de la relación laboral el "abandono del trabajo por parte del obrero". Se trataba de una referencia escueta, pero de contorno abiertos, destinada a sancionar toda ausencia del puesto de trabajo. No obstante, fue el Código de 1931 el primero en especificar qué debía entenderse por abandono, utilizando a este efecto una redacción muy similar a la que se señala en el actual artículo $160 \mathrm{~N}^{\circ} 4^{8}$. Y esa formulación se ha mantenido prácticamente igual en los textos laborales de las últimas décadas, sobreviviendo a numerosos y variados procesos de reforma legal.

Como ocurre casi siempre con nuestras causas disciplinarias de despido, el actual artículo $160 \mathrm{~N}^{\circ} 4$ rememora una hipótesis antigua, históricamente arraigada en los orígenes

\footnotetext{
5 Ambas referencias se encuentran en el artículo 160 No 3 CT. El mencionado precepto señala que el contrato de trabajo termina en el siguiente caso: "3. No concurrencia del trabajador a sus labores sin causa justificada durante dos días seguidos, dos lunes en el mes o un total de tres días durante igual período de tiempo; asimismo, la falta injustificada, o sin aviso previo de parte del trabajador que tuviere a su cargo una actividad, faena o máquina cuyo abandono o paralización signifique una perturbación grave en la marcha de la obra"

6 Artículo 120 CT.

7 Artículo $160 \mathrm{~N}^{\circ} 7 \mathrm{CT}$.

8 El artículo 9 N$^{\circ} 11$ del Código del Trabajo de 1931, señaló lo siguiente: "El contrato de trabajo termina: 11. Por abandono del trabajo de parte del obrero. Se entiende por abandono del trabajo: a) La salida intempestiva e injustificada del obrero del sitio de la faena y durante las horas de trabajo, sin permiso del patrón o de quien lo represente; b) La negativa de trabajar en las faenas a que ha sido destinado, siempre que estas estén de acuerdo con el respectivo contrato; y c) La falta injustificada o sin aviso previo, de asistencia al trabajo de parte del obrero que tuviere a su cargo una faena o máquina cuyo abandono o paralización signifique una perturbación en la marcha del resto de la obra".
} 
de la legislación laboral, y que no ha tenido un especial desarrollo doctrinario. A pesar de ello, la figura encierra un nutrido material interpretativo que permite adentrarse en los contornos de la causal.

En el presente artículo se busca acreditar que en las figuras de abandono por incumplimiento existe un hilo conductor común aplicable a todas las hipótesis de despido disciplinario. Ese hilo conductor se estructura, en primer lugar, en la concurrencia de la gravedad como un requisito indispensable de justificación de la causal. Asimismo, los supuestos de abandono reflejan una aceptación, al menos por parte de la jurisprudencia, de que la ocurrencia del hecho implica una infracción voluntaria a la buena fe contractual y un inexorable vínculo entre cargo e infracción. El estudio de que da cuenta este artículo también permite acreditar como los tribunales laborales han ido asumiendo la denominada teoría de la gradualidad, y superando la clásica doctrina contenida en el principio solve et repete (abriéndose paso a una idea más amplia del ius resistentiae). Estas hipótesis que se plantean en el artículo, logran probarse a través de un nutrido grupo de argumentaciones jurisprudenciales que se ha podido extraer de una amplia revisión de fallos emanados de tribunales superiores de justicia. Además, la referencia a doctrina -comparada y nacionalha permitido arribar a conclusiones generales que permiten estructurar los contornos del abandono por incumplimiento y uniformar criterios en torno al contenido esencial de la infracción. Más aun, la confrontación entre doctrina y jurisprudencia posibilita que en el presente artículo se propongan criterios ordenadores de aplicación de esta específica causa disciplinaria, jerarquizando los aspectos de valoración jurídica que subyacen en ella.

\section{LA SALIDA INTEMPESTIVA E INJUSTIFICADA DEL TRABAJADOR DEL SITIO DE LA FAENA Y DURANTE LAS HORAS DE TRABAJO, SIN PERMISO DEL EMPLEADOR O DE QUIEN LO REPRESENTE}

\section{LA SALIDA INTEMPESTIVA E INJUSTIFICADA}

Nuestro legislador ha sancionado como un primer supuesto infraccional -de abandono por incumplimiento- la salida intempestiva e injustificada del trabajador del sitio de la faena y durante las horas de trabajo, sin permiso del empleador o de quien lo represente. Esta figura sancionatoria parte de una hipótesis inicial: el contrato de trabajo le impone al trabajador no solo un tiempo o una duración de trabajo sino que también un deber de llevar a efecto un desempeño normal de sus labores ${ }^{9}$. De allí que, durante el desarrollo del vínculo laboral, el empleador debiese esperar no solo que su contraparte permanezca en su puesto de trabajo durante el horario convenido, sino que también que ejecute la prestación con efectividad ${ }^{10}$.

Gramaticalmente, la acción consistente en salir implica partir de un lugar a otro; en este caso, partir desde el sitio de la faena, haciendo abandono del mismo, de forma intempestiva. De esta manera, la expresión legal permite circunscribir la infracción en un partir indebido e inoportuno, fuera de tiempo y sazón, en medio de la jornada, cuestión

\footnotetext{
9 Véase Bidon y Vigil de Quiñones (2001) p. 356.

10 Véase por todos Alonso (1957) p. 137.
} 
que se aparta por completo de una salida correcta o justificada ${ }^{11}$. La salida, por tanto, deja al descubierto una interrupción de las labores convenidas mediante el retiro injustificado del lugar de trabajo ${ }^{12}$. Nótese, que aquello que sanciona el Código es la salida; pero nada dice con respecto al no retorno. De este modo, si un trabajador hace dejación de su puesto de trabajo de manera justificada, pero evadiendo el retorno debido, entonces la causal aplicable no podría ser la del artículo 160 No $4^{13}$.

La salida que se le reprocha al trabajador, sin ser definitiva, debe tener algún grado de permanencia o prolongación. Ello cumpliría con el test de gravedad que se exige en este tipo de infracciones. Por el contrario, las ausencias breves o momentáneas no alcanzan en principio a reunir una entidad suficiente y no pueden servir de fundamento para extinguir el contrato ${ }^{14}$, salvo que la salida reúna ribetes de gravedad ${ }^{15}$. Como señala un autor, siguiendo a la jurisprudencia norteamericana, el empleador puede poner término al contrato fundado en hechos trascendentes pero no en trivialidades ${ }^{16}$.

De forma copulativa, el Código también exige que la salida carezca de justificación. Esta exigencia de justificación permite resolver el test de culpabilidad de la conducta infraccional ${ }^{17}$, y evaluar el comportamiento del trabajador en razón de parámetros objetivos que permitan concluir si el abandono era o no reprochable. Desde esta perspectiva, la justificación requiere de la concurrencia de un precepto legal, de una disposición reglamentaria o bien de circunstancias especiales que dada su naturaleza explican el abandono en particular $^{18}$. Así, por ejemplo, la existencia de hechos ajenos a la voluntad del trabajador, y de los cuales no sea culpable, los supuestos de fuerza mayor propia o impropia que afecten al

11 Sentencia de la Corte de Apelaciones de Rancagua de 19 de octubre de 2007 (Rol No 200-2007). Vid. también sentencia de la Corte Suprema de 4 de noviembre de 2008 (Rol No 5813-2008); y sentencia de la Corte de Apelaciones de Puerto Montt de 9 de septiembre de 2013 (Rol N 99-2013).

12 Parte de la doctrina nacional (DAVIs $[\mathrm{s} / \mathrm{f}]$ p. 59) ha puesto como ejemplos de salida intempestiva el abandono que se produce durante el proceso de producción de una fábrica y con dejación de una labor que forma parte de dicho proceso; "cuando se interrumpe el desarrollo de las labores agrícolas dejando un tractor sin funcionar"; o cuando queda "algún mecanismo funcionando sin la presencia y la supervigilancia del dependiente llamado a controlarlo".

13 Sentencia de la Corte Suprema de 4 de octubre de 1968, así como el Informe emitido en esta causa por la Corte del Trabajo con fecha 15 de abril de 1968. RDJ, T. LXV (1968), SEC tercera, p. 160.

14 Sentencia de la Corte Suprema de 4 de abril de 1990. RDJ, T. LXXXVII (1990), SEC tercera, p. 28; y sentencia de la Corte de Apelaciones de 1 de agosto de 1991. GJ No 134 (1991), p. 144. En el plano doctrinario, véase Macchiavello (1986) p. 521; y Sala (2001) p. 18.

15 Véase el ejemplo de gravedad planteado en Aguilera (1997) p. 174: "Cuando el trabajador abandona su puesto de trabajo desatendiendo al enfermo que tiene a su cargo". A mayor abundamiento, vid. el ejemplo planteado por MuÑoz CAmpos (1986), p. 292, y que se extrae de la jurisprudencia comparada: "(...) el actor se ausentó de su puesto de trabajo, en la fecha de autos, durante largos espacios de tiempo, originando, con esa conducta abstencionista, que se produjeran averías en las máquinas de hilar que estaban a su cuidado y exigían una atención constante, con los perjuicios causados, en su consecuencia, a la empresa”.

16 Véase Martínez (1988) p. 141.

17 Véase Montoya (2008) p. 471.

18 Aguilera (1997) p. 255. 
dependiente, o el ejercicio de un derecho legal o contractual, permitirían ciertamente justificar una salida repentina desde el lugar de trabajo ${ }^{19}$.

La exigencia de justificación ha sido ampliamente desarrollada por la jurisprudencia, a raíz de la causal establecida en el artículo $160 \mathrm{~N}^{\circ} 3$. En ese contexto, los tribunales han recurrido al sentido natural y obvio de la palabra y lo reconducen a una razón o motivo suficiente que explique la conducta asumida por el trabajador. En palabras de la jurisprudencia, "la razonabilidad de los acontecimientos se erige como imprescindible, a la luz de lo que la doctrina ha denominado la 'sensatez del caso' y cuya amplitud abarca una multiplicidad de situaciones con un denominador común, cual es la amenidad en su gestación en relación al afectado" 20 . En el fondo, el estándar de justificación ha sido evaluado de forma amplia y flexible por la jurisprudencia, colocando el acento en la racionalidad del comportamiento del trabajador.

La circunstancia de que la ley exija que la salida sea justificada, no implica necesariamente que esta deba ser comunicada de forma previa al empleador ${ }^{21}$. El propio carácter intempestivo dificulta una necesaria notificación previa e impone a lo menos una acreditación posterior. Esa acreditación se vinculará probablemente con hechos independientes a la voluntad del trabajador, y que le impiden permanecer en el sitio de la faena. Dicho de otra forma, lo que refleja el núcleo de esta causal es que el abandono será injustificado "en la medida que responda solamente a una salida sin razón o carente de justificación durante las horas de trabajo, es decir, que el trabajador no haya tenido motivo o razón para retirarse de sus faenas. La normativa en ningún caso exige que la justificación importe noticiar al empleador por parte del trabajador del retiro de las faenas" 22 .

Dentro de la casuística jurisprudencial, las razones de salud han sido generalmente aceptadas como causa justificada de abandono, más aun si ellas se encuentran debidamente documentadas ${ }^{23}$. También se ha considerado justificado un mero abandono que no reúne la totalidad de los requisitos a que hace referencia el artículo $160 \mathrm{~N}^{\circ} 4$, o bien que las razones para no terminar el trabajo encomendado, y salir anticipadamente de las labores, radicaban en una prescripción médica anterior ${ }^{24}$. A mayor abundamiento, se tienden a justificar sa-

19 Aguilera (1997) p. 255. Véase también Gómez (2009) p. 137; Pedrajas y Sala (2009) p. 17; y Sempere (2001) pp. 123 y ss.

20 Sentencia de la Corte Suprema de 28 de julio de 2010. RFM No 554 (2010), p. 513; sentencia de la Corte Suprema de 24 de enero de 2006. RDJ, T. CIII (2006), SEC tercera, p. 225; y sentencia de la Corte Suprema de 7 de enero de 1982. RDJ, T. LXXIX (1982), SEC tercera, p. 1.

${ }^{21}$ Véase, entre otros, Fernández (1990) p. 1643; Gárate (1981) p. 213; y Álvarez (1995) p. 46.

22 Véase sentencia de la Corte de Apelaciones de Puerto Montt de 13 de diciembre de 2013 (Rol No 1442013).

${ }^{23}$ Una posición más rigurosa puede consultarse en la sentencia de la Corte de Apelaciones de Santiago de 11 de noviembre de 1994. RDJ, T. XCI (1994), SEC tercera, p. 271. En dicha oportunidad, al sentenciador no le bastó la simple invocación de problemas de salud por parte del trabajador: "La justificante de motivos de salud, puede efectivamente, ser acreditada mediante prueba instrumental, siempre que ella diga relación con los referidos motivos de salud, por ejemplo alguna constancia del servicio asistencial al que recurrió; pero en caso alguno mediante una fotocopia de la comunicación, dejada en el cuaderno de la garita, suscrita por el actor y el trabajador que lo reemplazaría".

${ }^{24}$ Ese fue el caso resuelto por la sentencia de 1 de octubre de 2013 de la Corte de Apelaciones de Concepción (Rol No 225-2013), la cual concluyó que "no se configura el requisito de injustificación de la salida, pues 
lidas que tienen su origen en el estado anímico o sicológico del trabajador, la situación de crisis que le toca enfrentar en razón de un quiebre matrimonial, la muerte de un familiar o la enfermedad de un hijo o de un cónyuge. Más aún, la propia doctrina y jurisprudencia han esgrimido como causa justificante la salida "de un obrero que va a buscar una pieza de repuesto o una herramienta que le falta para desempeñar el trabajo" 25 , el abandono para asistir al entierro de un compañero de labores ${ }^{26}$, la ocurrencia de eventos familiares que se pueden presentar de forma totalmente inesperada ${ }^{27}$, la ejecución de obligaciones civiles u obligaciones políticas de carácter personal e intransferible ${ }^{28}$, o la precaución asumida ante movilizaciones sociales ${ }^{29}$. En el fondo, lo que existe en todos estos casos justificantes es una evaluación más benévola sobre la gravedad de la conducta cuestión que lleva a concluir que la sanción aplicable no puede ser el despido. Por el contrario, no se ha considerado justificada la salida de aquel trabajador que no espero el relevo de otro guardia y que al mismo tiempo no contaba con la autorización expresa para retirarse de sus labores ${ }^{30}$; o que abandonó el trabajo "limitándose a darle cuenta a otro trabajador que no se sentía bien, estando en realidad ebrio" 31 .

En este orden de ideas, el permiso previamente denegado por el empleador ha tenido un tratamiento diverso. Si bien se reconoce un limitado "ius resistentiae" por parte del trabajador $^{32}$, en la mayoría de los casos se tiende a concluir que el ejercicio de vías de hecho por parte del dependiente - a objeto de ejercer su derecho- se opone a un funcionamiento adecuado de la organización productiva más aún si la negativa del empleador ha derivado de un ejercicio regular del poder de dirección ${ }^{33}$. Por lo demás, las decisiones empresariales

habiéndose determinado previamente que el día de su despido y al momento de retirarse el trabajador, tenía a su carga más de cuatro horas de trabajo y que el viaje que tenía que realizar, implicaba aproximadamente más de diez horas de trabajo, sumadas a las cuatro anteriores sin considerar los descansos obligatorios previstos en el artículo 25 bis del Código del Trabajo, unido a que ese mismo día concurrió al médico quien le otorgó la correspondiente licencia médica por presentar diversas patologías, de lo que brota sin lugar a dudas la razón que tenía el demandante para no haber terminado el trabajo encomendado para ese día, no teniendo relevancia el hecho que pocas horas antes haya ejecutado labores de carga u otras, por cuanto las máximas de la experiencia nos conducen a concluir que un trabajador, a pesar de estar padeciendo una enfermedad, puede realizar sus tareas laborales, aunque no sea lo debido, tal como se lo indicó el médico al otorgarle licencia médica y reposo ese mismo día por los dolores que presentaba". En igual sentido, sentencia de la Corte de Apelaciones de Talca de 1 de agosto de 1991. GJ N²134 (1991), p. 144.

25 Véase Davis (s/f) p. 59.

26 Véase García (1979) p. 905.

27 Véase BRIOnES (1995) p. 334

28 Álvarez (1995) p. 47. Entre las obligaciones civiles o políticas, el autor destaca por ejemplo las exigencias de auxilio a la autoridad y sus agentes, los deberes de socorro, o las citaciones para concurrir como testigo o perito en causa judicial.

29 Véase Walker (1990) p. 59.

30 Sentencia de la Corte de Apelaciones de Chillán de 8 de abril de 2014 (Rol N²1-2014).

31 Sentencia de la Corte de Apelaciones Presidente Aguirre Cerda de 27 de septiembre de 1984, en THAYER y Rodríguez (1988) p. 333.

32 Ortiz (2000) p. 1129. Véase también Albiol (1987) pp. 151 y ss; Pérez (1986) pp. 99 y ss; Pedrajas (1990) p. 385; BaYlos (2002) p. 37; y Morato (2011) p. 219.

33 Pedrajas y Sala (2009) p. 19; y Gómez (2009) p. 165. 
ejercidas dentro del ámbito regular gozan en principio de presunción de legitimidad cuestión que exige tomar en consideración el rechazo inicial ${ }^{34}$.

Sin perjuicio de lo señalado, y tal como se ha advertido doctrinariamente ${ }^{35}$, no cabe duda que el requisito de la justificación debe vincularse con un juicio de proporcionalidad y no de mera razonabilidad. De este modo, la justificación debe calificarse en función de un conjunto de criterios que permitan evaluar correctamente el comportamiento del trabajador y que han dado motivo a la salida que se le reprocha. Dentro de estos criterios de evaluación habrá que considerar si la falta en cuestión lesiona el interés contractual básico del empleador y que ha sido causa de la contratación ${ }^{36}$. Ese parece haber sido el criterio que siguió en su momento el fallo de la CS de 13 de agosto de 1992, el cual justificó la salida no autorizada de un trabajador, por parte de su empleador, "pues deseaba estar presente en la ceremonia de egreso de su hijo de la enseñanza técnico profesional" ${ }^{37}$; o bien el fallo de la misma CS de 2 de abril de 1986, el cual estimó que la salida del trabajador del sitio de la faena durante las horas de trabajo, sin permiso del empleador, para realizar un trámite impostergable relativo al contrato de prestación de servicios profesionales dirigidos a obtener el saneamiento del título de dominio de una propiedad, no cabía dentro de la hipótesis de la causal ${ }^{38}$.

\section{El REQUisito LOCATIVO Y TEMPORAL}

La salida intempestiva que se le reprocha al trabajador es aquella que se verifica dentro de un contexto locativo (“el sitio de la faena”) y temporal (“durante las horas de trabajo”). El requisito del lugar es coincidente con la configuración que nuestras primeras leyes sociales hacían del ámbito organizativo. Para ello, el lugar de trabajo se asociaba a un espacio físico determinado al cual el trabajador ingresaba y salía en razón de una jornada de tiempo trabajado. Con todo, en la actualidad la expresión resulta demasiado simple para entender el alcance de esta específica causa disciplinaria. En rigor, cuando el Código hace referencia al sitio de la faena lo que verdaderamente le está prohibiendo al trabajador es que haga abandono del entorno físico y organizativo donde presta los servicios.

La referencia al sitio de la faena no puede ser confundida con el puesto de trabajo ya que para ello al legislador le habría bastado con invocar la segunda parte de la causal

\footnotetext{
34 Luque (1999) p. 113; Dieguez (1971) p. 92; Gorelli (1998) p. 79; y SuÁrez (1969) p. 89. Una posición jurisprudencial contraria, aunque referida a las inasistencias, puede consultarse en la sentencia de la Corte Suprema de 24 de enero de 2006. RDJ, T. CIII (2006), SEC tercera, p. 225; y en la sentencia de la Corte de Apelaciones de Santiago de 19 de junio de 1995. RFM No 453 (1996), p. 1783.

35 Román (1992) p. 356. En igual sentido, Gómez (2009) p. 101.

36 Estos mismos criterios han llevado a que en determinados casos se atenúe o elimine la responsabilidad. Por ejemplo, en algunas hipótesis la antigüedad ha servido de justificación para salidas intempestivas. Véase FERNÁNDEZ (1990) p. 1643.

37 Véase sentencia de la Corte Suprema de 13 de agosto de 1992. RFM No 405 (1992) p. 569.

38 Véase sentencia de la Corte Suprema de 2 de abril de 1986. RDJ, T. LXXXIII (1986), SEC tercera, p. 11. En este caso en particular, la Corte concluyó que la salida intempestiva había sido justificada "dado el carácter impostergable del trámite (...) más aún que con ella no hubo abandono propiamente tal del trabajo, pues no dejó inconcluso o descuidó sus labores, ya que se reintegró a las mismas una vez cumplido el motivo de la salida, para continuarlas (...)".
} 
establecida en el artículo $160 \mathrm{~N}^{\circ} 3$ del Código, o bien asociar la salida intempestiva con un supuesto de incumplimiento grave de las obligaciones. Por el contrario, la expresión legal parece centrarse más en la figura de un abandono del centro de trabajo y no tanto en el cumplimiento específico de las tareas encomendadas para un determinado puesto. La figura del centro de trabajo objetiviza la infracción ${ }^{39}$, y permite incluir dentro de la hipótesis legal no solo un aspecto meramente geográfico sino que también uno que se relaciona con el ámbito organizativo. Si el trabajador abandonara sus tareas, y dejara el puesto de trabajo, entonces lo más lógico es que se asociara esta conducta con una negativa a trabajar sin causa justificada en las faenas convenidas. Es por ello que, parte de la jurisprudencia, ha vinculado la salida intempestiva con el lugar en que se prestan los servicios, rechazando la posibilidad de relacionar esta causal con el abandono de una tarea determinada ${ }^{40}$.

En cuanto al momento de la infracción, el Código es perentorio en exigir que la salida intempestiva se produzca durante las horas de trabajo. Se trata de una referencia evidente a la jornada laboral (sea esta ordinaria o extraordinaria), y que exige excluir todas aquellas salidas que no estén vinculadas con la ejecución misma de las labores convenidas en el contrato. Por ello, no puede considerarse un abandono la circunstancia que el trabajador salga del establecimiento antes de comenzar la jornada ordinaria o después de terminada esta ${ }^{41}$. Tampoco sería motivo de reproche la salida en tiempo de colación o bien para realizar cursos de capacitación legalmente establecidos ${ }^{42}$.

\section{LA INEXISTENCIA DE UN PERMISO POR PARTE DEL EMPLEADOR O DE QUIEN LO REPRESENTE}

La letra a) del artículo $160 \mathrm{~N}^{\circ} 4$ del Código, termina exigiendo un último requisito copulativo: que la salida se lleve a cabo "sin permiso del empleador o de quien lo represente”. Cuando el Código exige el permiso del empleador, lo está supeditando básicamente a una autorización formulada por la contraparte del contrato de trabajo. Dicha contraparte es el titular que actúa como acreedor laboral y que requiere de la prestación continuada por parte del dependiente.

No obstante, la condición de titular no tiene por qué suponer un ejercicio directo de los poderes respectivos. Si bien la titularidad básica o en sentido propio corresponde siempre al empleador que contrata por su cuenta o riesgo, y asume la condición de sujeto del contrato de trabajo, nada impide que el ejercicio de la misma sea encomendado en un representante o delegado.

\footnotetext{
39 ARIAS (2013) p. 36.

40 Sentencia de la Corte de Apelaciones de La Serena de 2 de septiembre de 2013 (Rol No 85-2013): "Que, a juicio de esta Corte, (...) del propio texto de la norma en comento resulta, sin lugar a dudas, que para su configuración se requiere que el trabajador salga o se retire en forma intempestiva e injustificada del 'sitio de la faena', entendiéndose por tal las dependencias en las que presta sus servicios, lo que no ha ocurrido en el caso sub lite, sin que baste para ello que simplemente deje de permanecer en el lugar específico en el que habitualmente labora al interior del local y, como en este caso, se niegue a realizar las funciones para las que fue contratado con motivo de realizar una manifestación en contra del empleador, conjuntamente con los demás compañeros de trabajo”. En el plano doctrinal, vid. además Rojas (2014) p. 359.

41 DaVIs (s/f) p. 59.

42 Véase sentencia de la Corte Suprema de 8 de agosto de 1980. RDJ, T. LXXVII (1980), SEC tercera, p. 20.
} 
Esta es la lógica que sigue el Código: se requiere de una autorización del titular o bien de un representante que tenga las facultades para otorgar el permiso. Algunos de esos representantes lo ha resuelto expresamente el inciso primero del artículo $4^{\circ}$ del Código, al señalar que se presume de derecho que representan al empleador el gerente, el administrador o el capitán de barco. No obstante, ese mismo artículo abre las hipótesis de representación empleadora al indicar que también tiene la calidad de representante aquella persona que "ejerce habitualmente funciones de dirección o administración por cuenta o representación de una persona natural o jurídica”. Lo que se exige, por lo tanto, es que el permiso en cuestión sea otorgado por una persona que real o formalmente ejerza el poder de dirección al menos en el ámbito necesario para validar la autorización.

En todo caso, cabe hacer presente que en la estructura actual del Código del Trabajo la existencia de la infracción no requiere de intimidación previa del empleador. Es decir, para que la salida intempestiva pueda ser reprochada no es necesario que el empleador imponga un reintegro dentro de plazos preestablecidos. El ilícito laboral se configura por la simple salida injustificada, más allá de si el empleador reconviene por el regreso antes de tomar una decisión extintiva ${ }^{43}$.

\section{II.- LA NEGATIVA A TRABAJAR SIN CAUSA JUSTIFICADA EN LAS FAENAS CONVENIDAS EN EL CONTRATO}

De forma complementaria a los supuestos de abandono abrupto e intempestivo, el Código también sanciona la negativa a trabajar en las faenas a que ha sido destinado el trabajador, siempre que estas estén de acuerdo con el respectivo contrato. Se trata de otro supuesto más de abandono y, tal como se ha dicho, su origen se remonta al mismo Código del Trabajo del año 1931. A partir de allí, la redacción legal se ha mantenido hasta nuestros días y ha sobrevivido a diversos procesos de reforma legal. No obstante, su actual redacción se la debemos a la Ley $\mathrm{N}^{\circ} 16.455$ la cual, manteniendo el diseño normativo de la causal, agregó un requisito esencial para comprender el alcance de esta hipótesis: la negativa debe ser "sin causa justificada" 44 .

\section{LA NEGATIVA A TRABAJAR, SIN CAUSA JUSTIFICADA}

La negativa injustificada a trabajar, es un caso típico de desobediencia e indisciplina. En la estructura del contrato de trabajo, el dependiente asume la obligación básica de realizar las tareas convenidas, y desde esta perspectiva la obediencia en la ejecución de las obligaciones resulta indispensable a objeto de alcanzar el programa contractual que las partes han acordado ${ }^{45}$. Este deber de obediencia se explica como contrapartida del poder de dirección del empleador ${ }^{46}$, y se afecta cada vez que el trabajador contraría las órdenes e

\footnotetext{
43 Véase, a nivel doctrinario, GÁrATE (1981) p. 208.

44 Artículo $2^{\circ} \mathrm{N}^{\circ} 7^{\circ}$, letra b), de la LEY $\mathrm{N}^{\circ} 16.455$.

45 García (1979) p. 862.

46 Entre otros muchos, Palomeque (1992) p. 145; Morato (2011) pp. 4 y ss; Mendez (1999) p. 73; Garrigues (2000b) p. 11; Gorelli (1998) p. 74, y Román (1992) p. 343.
} 
instrucciones contractualmente exigidas. La indisciplina, por su parte, se produce en todos aquellos casos en que el trabajador actúa de forma opuesta a lo que establece la normativa laboral. Desde esta perspectiva, la negativa injustificada a trabajar supone no solo un acto de desobediencia sino que, además, una infracción al deber anterior de cumplir con las obligaciones concretas del puesto de trabajo ${ }^{47}$.

Este deber básico de obediencia y disciplina no exige, necesariamente, de órdenes expresas de la contraparte del trabajador ${ }^{48}$; aun cuando en la práctica la celebración del vínculo laboral supone someterse a las instrucciones del empleador quien goza de un poder de dirección. Por el contrario, la gama de órdenes que pueden impartirse se presentan de manera positiva o negativa, generales o particulares, directas o delegadas, escritas o verbales, previas a la realización de las labores o coetáneas a las mismas, de carácter necesario o dispositivo ${ }^{49}$. Lo anterior permite concluir que la negativa a trabajar se refiere tanto a la no ejecución de las tareas convenidas así como al hecho de dejar de cumplir las órdenes e instrucciones que imparta el empleador o la persona a quien este le entregue facultades de dirección o mando.

Lo que ocurre es que, en el núcleo del poder directivo se concentran las atribuciones para dictar órdenes e instrucciones que permiten concretar las específicas obligaciones del trabajador. Y es el ejercicio del propio poder de dirección, así como del contrato propiamente tal, lo que obliga a que el trabajador realice la prestación debida, de la cual solo podrá eximirse cuando una orden sea completamente ilegítima, y no merecedora de obediencia ${ }^{50}$.

Por último, y como ya se ha dicho, las órdenes del empleador deben ser impartidas por el titular o quien lo represente. Desde esta perspectiva, toda orden impartida por un representante del empleador debe también ser obedecida por el trabajador. Solo por excepción, la jurisprudencia ha concluido que una orden que no fue impartida directamente por el empleador no le es oponible al trabajador ${ }^{51}$.

\subsection{El núcleo inicial de la infracción: la negativa a trabajar}

Para configurar el abandono, el Código exige en primer término la ocurrencia de un hecho concreto: negarse a trabajar. Y esta negativa se puede producir frente a órdenes concretas del empleador o bien por el no cumplimiento de la normativa básica. Lo anterior permite concluir que en la hipótesis del artículo 160 No 4 del Código subyace la sanción frente a hechos propios de desobediencia como también de indisciplina.

47 Palomeque (1992) p. 147.

48 Ortiz (2000) p. 1128; y Aguilera (1997) pp. 124 y 125.

49 Véase Montoya (1965) pp. 148 y ss.

50 Montoya (1985) pp. 138 y 139.

51 Así ocurrió en el fallo dictado por la Corte de Apelaciones de San Miguel de 21 de diciembre de 2009 (Rol N ${ }^{\circ}$ 482-2009), en que el sentenciador validó la conducta del trabajador al solicitar que la orden le fuera impartida por el dueño de la empresa, "ya que, no estaba cumpliendo la labor para la cual fue realmente contratado". A mayor abundamiento, véase también Gorelli (1998) p. 87: "Ocurre igual cuando se trata de una desobediencia a una orden dada por persona no legitimada para darla, en este caso tampoco existe deber de obediencia alguno, y no hay incumplimiento". 
La negativa, desde luego, puede manifestarse tanto de manera expresa o tácita, como por acción u omisión; pero lo relevante es que el trabajador se abstenga de ejecutar las labores que contractualmente le correspondían. Y esta negativa deja al descubierto una clara desobediencia que el Código sanciona con la extinción del contrato. Por cierto, la negativa del trabajador exige una voluntad inequívoca de este en orden a no ejecutar las labores asumidas en virtud del contrato, o bien desobedecer las instrucciones legítimas que imparta el empleador, de modo tal que no quepa duda que se esté ante un acto de desobediencia.

La negativa a trabajar requiere de una actitud intencionada, consciente y deliberada, por no hacer aquello que ordena el iter contractual ${ }^{52}$. Pero necesita, además, de la gravedad. Dicha gravedad se expresa por la concurrencia de dos rasgos básicos: obligatoriedad y claridad de una orden empleadora ${ }^{53}$, de modo tal que de la negativa a trabajar y a cumplir las órdenes del acreedor laboral se trasunta de manera evidente la conducta de infracción disciplinaria. Probablemente, una negativa puntual, más bien irrelevante dentro del programa contractual, no alcance la entidad suficiente para justificar la extinción del vínculo ${ }^{54}$. Incluso, alguna jurisprudencia ha exigido para configurar la causal que la negativa sea total ${ }^{55}$. Tampoco se alcanzará ese ribete de gravedad cuando ha existido una conducta empleadora de tolerancia, salvo que se advierta previamente sobre el fin de esa permisividad ${ }^{56}$; o cuando se han realizado actos posteriores tendientes a retomar las funciones y así matizar los efectos de la infracción ${ }^{57}$.

Por el contrario, el mantenimiento de una actitud de desobediencia, o la provocación de un daño (v. gr., a la reputación de la empresa, a terceros o a la organización empresarial), debieran reconducir al cumplimiento del requisito de la gravedad ${ }^{58}$. También debieran ser consideradas graves aquellas negativas que provocan desorganización en la empresa,

52 Entre otros, Dieguez (1971) p. 88; Garrigues (2000b) p. 34; Palomeque (1992) pp. 148 y 159; y MUÑoz (1986) p. 277. A nivel jurisprudencial, véase sentencia de la Corte de Apelaciones de Rancagua de 4 de noviembre de 2013 (Rol N 128-2013).

53 Véase Gómez (2009) p. 191. Y agrega en p. 192: "La falta de claridad en la orden o instrucción rebaja considerablemente la gravedad de la desobediencia”.

54 Un caso de esas dimensiones resolvió la sentencia de fecha 28 de marzo de 1984, dictada por la Corte de Apelaciones Presidente Aguirre Cerda (en Thayer y Rodríguez [1988] p. 333). Según la Corte, la circunstancia de haberse sorprendido al trabajador jugando a la pelota en horas de trabajo no constituye causal suficiente de despido "en atención a que el haber sido sorprendido por una sola vez en la actitud mencionada no puede constituir (...) abandono del trabajo, dados los términos en que se sanciona tal causal por la legislación vigente”. En igual sentido, RodríGUEZ-PIÑERo (1988) p. 13, quien puntualiza que una simple desobediencia que no encierra una actuación exageradamente indisciplinada, no puede ser castigada rigurosamente con el despido.

55 Sentencia de la Corte de Apelaciones de Santiago de 22 de julio de 1991. GJ Nº 133 (1991), p. 112.

56 Gil (2005) p. 1460. Véase también, Gorelli (1998) p. 107.

57 El caso resuelto por la sentencia de la Corte de Apelaciones de Concepción de 30 de noviembre de 2007 (Rol N ${ }^{\circ}$ 125-2007), en que un profesor despedido "apareció ese mismo día entregando diplomas a los alumnos del curso (...). Esta pura declaración destruye el fundamento fáctico de la causal”. Véase además sentencia de la Corte de Apelaciones de Antofagasta de 16 de febrero de 2015 (Rol N ${ }^{\circ}$ 197-2014). Una tesis doctrinaria en contrario, basada en jurisprudencia comparada, puede consultarse en GARRIGUES (2000b) p. 35.

58 Incluso, dogmáticamente, se ha considerado circunstancia agravante cuando la negativa a prestar servicios se lleva a cabo en presencia de compañeros de trabajo o de clientes "pues la publicidad del incumplimiento puede afectar la organización y prestigio de la empresa” Véase GARCíA-NúÑEz (2005) pp. 1828 y 1829. 
si repercuten de manera significativa en su funcionamiento, si se plantean con publicidad ${ }^{59}$; o, por último, si se llevan a cabo en circunstancias claramente agravantes (v. gr., negarse a desempeñar las labores convenidas a bordo de un buque o aeronave; cuando el trabajador desobediente desempeña un cargo de responsabilidad; o bien cuando el trabajador que se niega a trabajar tiene la calidad de representante de los trabajadores) ${ }^{60}$. En todos estos casos, la evaluación doctrinaria y jurisprudencial permite concluir que la gravedad emana tanto de la reiteración de la negativa, de la exigencia de mayores grados de disciplina en razón de la actividad, así como de una rebeldía a obedecer una orden legítima manifestada de forma expresa e inequívoca ${ }^{61}$.

Un caso reincidente de evaluación de la gravedad, se ha podido observar en la paralización colectiva de funciones sin respaldo legal. Durante la vigencia del Código de 1931, la jurisprudencia había asumido el criterio de sancionar estas figuras consideradas de por sí graves. Por ello, en determinados casos se sancionó la negativa de los obreros a trabajar en sus actividades ordinarias, "pues no entraron al local en que desempeñaban sus labores" 62 . Durante ese mismo período, se concluyó que la participación en una huelga ilegal "constituye una falta injustificada de asistencia al trabajo", validando la extinción contractual de las personas involucradas ${ }^{63}$.

No obstante, durante la aplicación del actual Código del Trabajo ha existido una valoración más matizada de la gravedad en lo que respecta a las paralizaciones colectivas. En efecto, se han considerado justificadas ciertas negativas a trabajar como aquella en que un grupo de trabajadores llevó a cabo una manifestación colectiva de hecho al interior de un terminal de autobuses, en la que participaron nueve trabajadores, "entre las 13:15 y 13:50 horas, período en el cual, no sacaron las máquinas a su cargo para realizar los recorridos correspondientes, paralización que fue pacífica y no impidió u obstruyó el libre tránsito de los no adherentes ni se produjeron hechos de violencia en el transcurso de la misma”. Esta paralización, según se dejó constancia en el fallo, tuvo su razón de ser en la demanda de pretensiones de interés común y defensa de intereses particulares agraviados con amenaza de despido en caso de incumplir la firma de un contrato de arrendamiento sobre las máquinas. El trabajador despedido "después de un periodo de detención, retornó a sus labores normales por iniciativa propia, prestando servicios efectivos desde las 7:51 hasta las 10:49 en jornada matutina y las 13:47 a las 20.17 horas, esto es, a lo menos, 9 horas, mientras que estuvo con detención, causalmente vinculada a la paralización, una fracción cercana a

59 Dieguez (1971) pp. 97 y 98.

60 Véase Aguilera (1997) pp. 147 y 148.

61 A nivel doctrinario, entre otros, Ortiz (2000) p. 1130; Gómez (2009) p. 192; Palomeque (1992) p. 155; Gorelli (1998) pp. 104 y 105; y García (1979) pp. 884 y ss.

62 Sentencia de la Corte Suprema de 6 de agosto de 1936. RDJ, T. XXXIII (1936), SEC primera, p. 418.

63 Sentencia de la Corte Suprema de 12 de enero de 1934. RDJ, T. XXXI (1934), SEC primera, p. 223. En igual sentido, sentencia de la Corte Suprema de 16 de octubre de 1961. RDJ, T. LVIII (1961), SEC tercera, p. 85; y sentencia de la Corte Suprema de 14 de diciembre de 1961. RFM No 37 (1961) p. 276. Los propios comentaristas del Código de 1931 ya afirmaban que el "paro de hecho, no significa otra cosa, precisamente, que la negativa a trabajar en las labores o faenas convenidas” (Véase DAVIs [s/f] p. 59). 
IRURETa URIarte, Pedro — "La salida intempestiva y la negativa a trabajar: Un supuesto de abandono..."

3 horas"64. La misma lógica se siguió en el caso de un grupo de trabajadores que no ingresaron a las dependencias de la empresa al inicio de su jornada de trabajo, "permaneciendo en la vía pública por un par de horas, retomando sus funciones habituales dentro de esa misma mañana, luego de sostener una reunión sus representantes con el Gerente”. En este último caso en particular, la jurisprudencia concluyó que "la situación fáctica descrita, en la que un grupo de trabajadores se manifiesta protestando por reivindicaciones laborales, estimando evidentemente no tener muchas posibilidades de ser oídos de otro modo, requiriendo la presencia de un representante del empleador para plantear sus problemas y solucionándose el conflicto luego de ser escuchados, no encuadra estrictamente con la causal del artículo $160 \mathrm{~N}^{\circ}$ 4"65. Similar línea argumental se siguió en un caso en que la negativa a trabajar se fundaba en un contexto de defensa de derechos laborales ${ }^{66}$, de exigencia de diálogo con el empleador ${ }^{67}$, o de movilización de un grupo de trabajadores que pertenecía a un sindicato "para presionar por una respuesta frente a estas reivindicaciones y como parte de esta presión”68.

Lo que subyace en estas alternativas jurisprudenciales es la aplicación de la tesis gradualista, en virtud de la cual el estándar de gravedad se califica en base a las circunstancias que han rodeado la ejecución del acto reprochado, su contexto así como el desarrollo de los hechos. Ello permite separar la aplicación de una causa justificada de término de la relación de un mero incumplimiento contractual. Más aun, esta tesis obligaría a distinguir supuestos tales como paralización activa y pasiva, o bien huelgas ilegales derivadas de su desarro-

64 Véase sentencia de la Corte de Apelaciones de Antofagasta de 16 de febrero de 2015 (Rol No 197-2014).

${ }^{65}$ Véase sentencia de la Corte de Apelaciones de Santiago de 7 de septiembre de 2012 (Rol No 594-2012). En esta misma sentencia, el voto de mayoría concluyó que "el movimiento gremial producido en este caso no carece del todo de justificación, si se tiene presente que la sentencia establece, (...) que el motivo de esta manifestación pacífica tuvo su origen en problemas relacionados con el pago de sus remuneraciones". Por el contrario, en otro supuesto de hecho análogo la CS concluyó que la negativa a trabajar por no pago de remuneración carecía de justificación: "Que, a juicio de esta Corte, la circunstancia que el empleador adeudare remuneraciones a sus trabajadores, no constituye una causal de justificación para que los demandantes se hayan negado a trabajar, pues la misma ley laboral contempla el ejercicio de una acción en su favor para el evento que su empleador, entre otras, no dé cumplimiento a las obligaciones que emanan del contrato de trabajo, como es encontrarse en mora en el pago de las remuneraciones" (sentencia de la Corte Suprema de 26 de enero de 2006. Rol $\mathrm{N}^{\circ}$ 4413-2004). En el fondo, lo que está en juego en este caso es determinar si el interés del empleador expresado a través del poder disciplinario, puede ser defendido en aquellos supuestos en que la empresa no ha cumplido con sus obligaciones contractuales básicas. Ante este dilema, el fallo de la Corte de Apelaciones de Santiago de 7 de septiembre de 2012 se alinea por la tesis de que el empleador no estaba en condiciones de desplegar todo su poder disciplinario, el cual se encontraba debilitado o restringido por su incumplimiento en el pago de las remuneraciones. Este mismo incumplimiento, según el primer fallo citado, atenúa la gravedad de la falta.

${ }_{66}$ Véase sentencia de la Corte Suprema de 8 de abril de 2008 (Rol N 588-2008): “(...) puesto que si bien es efectivo que los actores se negaron a trabajar en las faenas convenidas en sus contratos de trabajo, tal negativa fue justificada, por haberse producido en un contexto de defensa de sus derechos laborales, existiendo por ello una causa o un motivo plausible para no realizar las labores convenidas".

67 Sentencia de la Corte de Apelaciones de Concepción de 16 de agosto de 2011 (Rol No 205-2011). Y el mismo fallo agregó: "Si el propio empleador participó en este dialogo, estando conteste que el lapso de tiempo que se imputa sin trabajar fue dedicado a esto, validó la actuación de los trabajadores y su negativa resulta justificada, no pudiendo aprovecharse, actuando de buena fe, en esta circunstancia".

68 Sentencia de la Corte de Apelaciones de Antofagasta de 3 de agosto de 2005 (Rol No 115-2005). 
llo o de su misma convocatoria. Con todo, parte de la doctrina, sobre todo comparada, tiende a rechazar esta alternativa bajo el argumento de que este tipo de calificaciones jurisprudenciales obedecen a otro esquema histórico, más propios de los regímenes autoritarios, en que las huelgas se encontraban lisa y llanamente prohibidas. Pero en un régimen democrático, con fuerte reconocimiento del derecho de huelga, la paralización ilegal se encontraría fuera de todo amparo del ordenamiento jurídico ${ }^{69}$.

\subsection{La falta de justificación}

La negativa a trabajar tiene que tener un fundamento, una causa justificada. Como ya se ha dicho, esa exigencia permite aprobar el test de culpabilidad, y concluir que el accionar del trabajador se encuentra dentro de las alternativas que el ordenamiento permite. Y esa hipótesis se verifica cada vez que el trabajador invoque un derecho legítimo, o bien cuando exista una causa legal, reglamentaria o convencional que lo habilite ${ }^{70}$.

La jurisprudencia, en todo caso, tradicionalmente ha sido más rigurosa en la invocación de la causa justificada. En efecto, nuestros tribunales en determinados casos no concuerdan por lo general en que sea el propio trabajador quien pretenda atribuirse para sí la calificación del fundamento, ya que ese mérito solo le corresponde en definitiva al órgano jurisdiccional ${ }^{71}$. Lo que subyace en este criterio es la idea de que la desobediencia legítima debe considerarse una herramienta de "ultima ratio, subsidiaria al planteamiento de la correspondiente queja o reclamación"72. Y este criterio se vincula con la tesis de los propios tribunales en orden a que el trabajador no puede determinar por sí solo la legalidad o ilegalidad de una orden. En el fondo, la jurisprudencia nacional, en su versión clásica, ha actuado sobre la base que toda orden emanada del poder regular de dirección debe ser obedecida por el trabajador; y si discrepa de la legalidad de la misma, entonces debe ejercer los procedimientos de reclamo que el propio ordenamiento ha establecido. Con ello se evita, en la lógica implícita de esta jurisprudencia, que toda orden empresarial sea previamente

\footnotetext{
${ }_{69}$ Véase DuRán (2013) pp. 21 y ss. Y el mismo autor agrega en p. 27: "Cuando la huelga se ejerce (...) fuera de los márgenes legales establecidos para avalar su legalidad, el incumplimiento contractual de los trabajadores ni está justificado ni goza de tutela y protección del Derecho". Para un análisis más general de esta temática, vid. también CAMPS (1981) pp. 13 y ss; y MarTínez (1992) p. 337.

70 Sentencia de la Corte Suprema de 31 de julio de 2000. RDJ, T. XCVII (2000), SEC tercera, pp. 141 y ss.

71 Véase, en esta línea, el caso resuelto por la sentencia de la Corte de Apelaciones de Rancagua de 5 de agosto de 2010 (Rol N 95-2010). En dicha ocasión, el chofer de un camión en panne decidió permanecer en el taller de la empresa a fin de asistir al mecánico que realizaba las reparaciones del caso. En estas circunstancias, se le ordenó en dos oportunidades conducir otro camión con el fin de transportar alimento para las aves de la empresa, a lo que se negó, aduciendo que, si permanecía en el taller, recibiría como pago un "bono de taller", ascendente a la suma de ocho mil quinientos pesos (\$ 8.500.-), en tanto que si realizaba el transporte encargado, recibiría únicamente el "pago por vuelta", equivalente a tres mil pesos (\$3.000.-). A juicio de la Corte, el trabajador fue contratado para llevar a efecto labores de chofer, sin que para esto tuviera un camión asignado de manera exclusiva en el contrato, de manera que, si bien se dejaba a su cargo un camión determinado, no era esto un impedimento para que el empleador requiriera sus servicios en un camión distinto. Así las cosas, "resulta incuestionable que el trabajador, al negarse a realizar los viajes encomendados, no estaba ejerciendo un derecho legítimo de opción sino que lisa y llanamente desobedeció las órdenes impartidas por su empleador". Criterios similares pueden consultarse, también, en la sentencia de la Corte de Apelaciones de Santiago de 21 de marzo de 2011 (Rol No 1500-2010).

72 Véase Gómez (2009) p. 170
} 
judicializada a efectos de determinar su validez (cuestión que podría ser cuestionada, en todo caso, con el derecho a la tutela judicial efectiva).

Este criterio jurisprudencial se construye bajo la misma tesis que se ha esbozado en el Derecho comparado y que se resume en el principio "obedece y luego reclama" (solve et repete $)^{73}$. Este principio se ha intentado justificar básicamente en dos criterios: mantener la disciplina de la empresa y negarle al trabajador la posibilidad de que él se erija en el definidor de sus propias obligaciones ${ }^{74}$. Y en su versión tradicional ha permitido aceptar la presunción de legitimidad de la orden empleadora, salvo casos de peligrosidad o de manifiesto y objetivo abuso de derecho ${ }^{75}$.

Teniendo presente el criterio anterior, la casuística jurisprudencial se ha encargado de verificar supuestos de negativa injustificada al señalar que existiría abandono por incumplimiento en la circunstancia de negarse el trabajador a prestar servicios debido a que se le trasladaría correctamente de instalaciones ${ }^{76}$; el negarse a participar en una reunión del área a la cual pertenecía la trabajadora, "como era el aseguramiento de la calidad de la producción, junto al gerente y a un asesor externo de la empresa, la cual era de gran importancia, dado que su objetivo era solucionar irregularidades"77; así como las constantes faltas a sus labores consistentes "en llegar tarde o irse antes de las respectivas horas de entrada y salida como también no realizar las labores que les encomendaban"78. En todos estos casos, a pesar de que las instrucciones pudiesen carecer de racionalidad o desmerecer de la suficiente fundamentación, de todas formas los tribunales chilenos aplicaban el principio del solve et repete estimando que el trabajador tenía la obligación de obedecer la orden más allá de si se reclama con posterioridad de la misma.

Como es ampliamente sabido, el principio solve et repete es una construcción originaria del Derecho público, y que se funda en la inmediata ejecutividad de un acto administrativo. Trasplantada al ámbito laboral, el principio en su versión tradicional reflejaba una idea autoritaria de la empresa en que la sanción del empleador representaba una garantía de su poder disciplinario ${ }^{79}$. Con el transcurso del tiempo, esa lógica ha permanecido implícitamente en la valoración jurisprudencial del deber de obediencia construyendo un discurso que se funda en una seudopresunción inicial de legitimidad frente a toda orden del empleador.

Con todo, llevado al extremo, el principio solve et repete presenta un evidente desequilibrio pues solo se coloca en la hipótesis que al trabajador no le corresponde definir el alcance de sus obligaciones. Claramente, la configuración del deber de obediencia no puede implicar que el empleador sea el único sujeto apto para calificar el contenido obligacional del contrato celebrado con el trabajador. De allí que, en materia laboral, el principio solve

\footnotetext{
73 Por todos, Aguilera (1997) pp. 126 y ss; Gorelli (1998) pp. 77 y ss; Rodríguez-Piñero (1988) p. 11; Román (1992) pp. 351 y ss; y Morato (2011) p. 145.

74 Véase, por todos, Román (1992) p. 351.

75 Rodríguez-Piñero (1988) pp. 11 y 12; y Rodríguez (1974) p. 271.

76 Sentencia de la Corte de Apelaciones de Temuco de 29 de octubre de 2012 (Rol No 211-2012).

77 Véase sentencia de la Corte de Apelaciones de La Serena de 7 de diciembre de 2012 (Rol N 95-2012).

78 Sentencia de la Corte de Apelaciones de Santiago de 20 de mayo de 2014 (Rol No 1906-2013).

79 Baylos (2002) p. 33.
} 
et repete ha debido evolucionar hacia un sistema de delicado equilibrio en que se armonice la presunción de legitimidad de una orden empleadora con el ius resistentiae. Desde esta perspectiva, el deber de obediencia del trabajador se explica dentro del ejercicio regular del poder de dirección del empleador. Fuera de ese ejercicio regular, se despliega la figura de la desobediencia justa. En caso contrario, cualquier orden del empleador, independiente de su naturaleza, tendría que ser acatada.

El problema del principio solve et repete es que necesariamente obliga a establecer ciertas limitaciones, en cuanto a su real aplicación, ya que en la práctica solo admitía como fundamento de la desobediencia la circunstancia de que el empleador impartiera órdenes que evidentemente carecían de legitimidad. Pero esa lógica que subyace en el principio es insostenible ${ }^{80}$. Por ello, doctrinariamente ${ }^{81}$, se construyeron tres tipos de críticas a la idea de que las órdenes empleadoras deben aplicarse bajo un estricto apego al solve et repete. La primera de ellas se vincula con la indefensión en la cual queda el trabajador. Resulta evidente que si la única alternativa que este tiene es el reclamo a posteriori, entonces cualquier orden tendrá que ser previamente obedecida independientemente del contenido de la misma. En segundo lugar, de aceptarse una idea rígida de este principio se termina ampliando de hecho el poder de dirección del empleador, trasladando la evaluación del caso a la sola conducta del trabajador. Como ya se ha dicho, en ninguna hipótesis el poder del empleador puede ser visto como un haz de derechos absolutos e ilimitados, y que cualquier orden por él impartida deba ser tachada inicialmente de válida. Por último, en el principio solve et repete se cuestiona la idea de querer trasladar al ámbito laboral figuras que claramente pertenecen al derecho público y que a fin de cuentas terminan siendo desdibujadas.

En parte por estas y otras críticas, la jurisprudencia ha venido declarando como indebido el despido de un trabajador que se encontraba legal y válidamente impedido de realizar un viaje a Santiago ordenado por la empleadora, por cuanto se encontraba sometido a un tratamiento antidepresivo con fármacos psicotrópicos y de haberse verificado el traslado referido, "el demandante habría infringido las normas de la Ley del Tránsito que establecen los delitos, contravenciones y presunciones de responsabilidad en relación a quienes conduzcan en las condiciones descritas" 82 . También se ha declarado indebido el término del contrato si el trabajador acredita la existencia de antecedentes físicos o de salud que justificaban su negativa ${ }^{83}$. O bien, cuando la orden afecta derechos irrenunciables del trabajador, atenten contra su dignidad ${ }^{84}$, sean ilegales ${ }^{85}$, ajenas al ámbito laboral, manifiestamente

80 Véase, por todos, Pérez (1986) pp. 95 y ss.

81 Véase, por todos, Román (1992) pp. 353 y ss.

82 Sentencia de la Corte Suprema de 18 de marzo de 2009 (Rol No 7977-2008).

83 Sentencia de la Corte de Apelaciones de Chillán de 12 de diciembre de 2013 (Rol No 109-2013), en que la causa esgrimida por el trabajador para negarse a realizar las labores que se le ordenaban era que había padecido un infarto agudo "el que si bien en la actualidad se encuentra compensado y relativamente autónomo en las actividades cotidianas debe abstenerse de realizar actividad física extenuante". Por el contrario, a nivel comparado se ha considerado injustificada la desobediencia fundada en razones de salud, "cuando los órganos administrativos competentes han descartado la calificación de incapacidad permanente" Véase Gómez (2009) p. 177.

${ }^{84}$ Véase Ferrante (2001) pp. 73 y ss.

${ }^{85}$ En ese campo caería, por ejemplo, el despido de un trabajador por negarse a laborar en día domingo aun cuando no está exceptuado del descanso dominical de conformidad con el artículo 38 CT. En la misma 
IRURETa URIarte, Pedro — "La salida intempestiva y la negativa a trabajar: Un supuesto de abandono..."

abusivas $^{86}$ o que impliquen peligrosidad ${ }^{87}$. Más aun, doctrinariamente se ha reconocido el derecho de los trabajadores a desobedecer una orden que restrinja o impida el ejercicio de funciones sindicales ${ }^{88}$, o que se funden en una desobediencia técnica de carácter principalmente subjetivo ${ }^{89}$. Todos estos supuestos podrían resumirse en la idea que el trabajador puede legítimamente negarse a cumplir una orden cuando la instrucción del empleador ponga en peligro la vida o seguridad de las personas ${ }^{90}$, cuando la misma atenta en contra de derechos fundamentales del dependiente (v. gr., una orden humillante ${ }^{91}$ ) o sean discriminatorias ${ }^{92}$, o bien cuando la aceptación de la orden implique la comisión de un delito o de una conducta prohibida ${ }^{93}$. Todo ello reconduce a que el trabajador funde su negativa a

situación se encontraría el menor de dieciocho años al cual se le ordena prestar servicios en horario nocturno (artículo 18 CT), o la mujer que se encuentra gozando del descanso de pre y postnatal (artículo 195 CT).

86 Véase García-Núnez (2005) p. 1823; Garrigues (2000a) p. 45; Gorelli (1998) p. 95; y García Ninet (1979) p. 890. Un caso reincidente de desobediencia justificada, en la jurisprudencia y en la dogmática, se verifica en el supuesto de negarse el trabajador a prestar servicios durante días u horas extraordinarias (por todas, sentencia de la Corte de Apelaciones de San Miguel de 13 de marzo de 1997. Repertorio de Legislación y Jurisprudencia Chilenas. Código del Trabajo y Leyes Complementarias, T. I [2002] p. 57). Por excepción, debe entenderse obligado el trabajador a prestar servicios cuando la jornada extraordinaria se encuentra fundada en un legítimo uso del ius variandi. Así ocurre, por ejemplo, en el caso regulado por el artículo 29 CT, en que el legislador acepta expresamente que se pueda exceder la jornada ordinaria, "pero en la medida indispensable para evitar perjuicios en la marcha normal del establecimiento o faena, cuando sobrevengan fuerza mayor o caso fortuito, o cuando deban impedirse accidentes o efectuarse arreglos o reparaciones impostergables en las maquinarias o instalaciones".

${ }^{87}$ Véase CÁmara (1996) p. 2767, quien refiere el criterio de una sentencia comparada la cual señalaba que "el deber de obediencia no se extiende al cumplimiento de aquellas órdenes que, por suponer graves e innecesarios riesgos, provocados por el empleador a través de no observar la normativa vigente en materia de Seguridad e Higiene, devienen en ilícitas, lo que permite configurar el doctrinalmente denominado ius resistentiae, como derecho del trabajador a negar la prestación de sus servicios en el supuesto indicado". Y a continuación, agrega los requisitos para el ejercicio legítimo del ius resistentiae: "a) debe partirse de la objetiva existencia de un riesgo, siendo insuficiente la creencia subjetiva del trabajador (...); b) dicho riesgo debe ser grave (...), innecesario (...), e inevitable o si evitable 'no se hayan adoptado los mecanismos necesarios para ello, con infracción de las normas de seguridad existentes; c) además, el trabajador debe haber comunicado su decisión motivadamente". En relación con esta misma temática, vid. también GarCia y GonZÁlez (1996) pp. 2771 y ss; Morato (2011) p. 241; y $\operatorname{Cos}(2010)$ pp. 79 y ss.

88 Aguilera (1997) p. 177.

${ }^{89}$ Véase GARCía (1979) p. 896. La desobediencia técnica subjetiva es aquella que adoptan trabajadores muy cualificados, "fundada en el temor al descrédito profesional por causa de los nefastos resultados que podrían seguirse de cumplir estrictamente la orden impartida". La desobediencia técnica objetiva, por su parte, es aquella que "se funda en las posibles consecuencias que para la propia empresa produciría el hecho de seguirse las instrucciones empresariales o de sus representantes, e incluso los posibles daños a terceros".

90 Gorelli (1998) p. 90. Véase, en esta línea, el comentario a una sentencia dictada en Francia por la Cour de cassation, ch. sociale, de 23 de abril de 2003, en SAVATIER (2003) p. 805. En este caso, los choferes de autobuses de una empresa de transporte urbano decidieron paralizar su actividad y no ejecutar las labores convenidas en reacción a los continuos ataques de los cuales eran víctimas y que afectaban su integridad.

91 Aguilera (1997) p. 132. En el plano normativo, artículo $5^{\circ} \mathrm{CT}$.

92 Baylos (2002) p. 40. El mismo autor incorpora como ejemplo recurrente de órdenes vulneradoras de derechos fundamentales, o discriminatorias, las que pretenden impedir la eficacia de los derechos de libre sindicación y de huelga; las órdenes sobre las costumbres o vida privada del trabajador; o las que importan discriminación de género. Otros ejemplos relacionados pueden verse en Garrigues (2000b) pp. 18 y ss.

93 Por todos, Fernández (1981) pp. 53 y ss. 
trabajar en circunstancias objetivas ${ }^{94}$. Dicho de otra manera, lo que se distingue en todos estos criterios jurisprudenciales y dogmáticos es una aceptación de la tesis de la desobediencia justa, que deja de lado un criterio de obediencia absoluta, sin excepción, y que permite que el trabajador se oponga a instrucciones que desbordan el poder de dirección del empleador ${ }^{95}$. A mayor abundamiento, esta tesis intenta equilibrar la equivocada creencia de un ejercicio arbitrario y omnímodo del poder de dirección así como un control de análoga naturaleza por parte del trabajador frente a cualquier orden de su empleador ${ }^{96}$.

\section{LAS FAENAS CONVENIDAS EN EL CONTRATO}

Las tareas a las cuales se refiere la letra b) del artículo $160 \mathrm{~N}^{\circ} 4$, se vinculan con aquellas que señala el respectivo contrato de trabajo. Este contrato delimita los poderes del empleador así como las obligaciones del trabajador, con respecto a su respectivo cargo o función ${ }^{97}$. Por ello, si el trabajador no cumple las obligaciones concretas del puesto de trabajo, entonces se afecta el deber de obediencia y de buena $\mathrm{fe}^{98}$. Más aun, la explícita referencia que el Código realiza al contrato remarca el carácter contractual de cualquier orden del empleador, y excluye aquellas que se relacionan con aspectos extralaborales ${ }^{99}$.

En este orden de ideas, las faenas convenidas en el contrato constituyen una cláusula esencial, de conformidad con el artículo 10 No 3 CT. Lo anterior no obsta, de acuerdo al mismo precepto legal, a que el contrato pueda señalar dos o más funciones específicas, sean estas alternativas o complementarias ${ }^{100}$. De esta forma, las tareas convenidas centran el contenido obligacional exigible al trabajador y permiten determinar el ejercicio regular del poder de dirección. Asimismo, centra una eventual desobediencia en el marco de un incumplimiento contractual frente al ejercicio regular del poder de dirección ${ }^{101}$.

Lo anterior ha llevado a que la jurisprudencia valide, por regla general, cualquier negativa del trabajador a realizar funciones o tareas que no se consagran en el referido contrato. Así ocurrió, por ejemplo, cuando un trabajador abandonó un curso de capacitación dictado por la empresa, del cual tampoco se encontraba acreditada la obligación del depen-

\footnotetext{
94 En el plano doctrinario, Gómez (2009) p. 175; y Morato (2011) pp. 77 y ss.

95 Por todos, Montoya (2008) p. 328. Del mismo autor (1965) p. 253. Véase también Aguilera (1997) p. 134: “(...) se entiende plenamente admisible un ius resistentiae en todos aquellos casos en que la negativa se presente razonable (...)". Y se agregan los siguientes ejemplos Aguilera (1997) p. 138: "Cuando el trabajador deja de cumplir la orden recibida al creer de buena fe y con alguna base objetiva que la misma carece de legitimidad"; "Cuando la orden (...) va dirigida a persona que carece de legitimidad para llevarla a cabo"; "Cuando la orden del empresario, (...), no puede realizarse por el trabajador al ser imposible técnicamente"; y "Cuando la orden empresarial no se cumple por razones familiares o personales".

96 Véase Montoya (2000) p. 588.

97 Desde luego, siendo esencial la determinación de la prestación de trabajo en el contrato, este no agota la completa y definitiva delimitación. Para ello se requiere de una sucesiva y necesaria serie de actos que se concretan a partir de órdenes e instrucciones del empleador. Sobre el particular, véase Montoya (2011) pp. 36 y 37 .

98 Aguilera (1997) p. 173, y García (1979) p. 859. Véase también Delgado (1992) pp. 125 y ss.

99 Véase, en el plano doctrinario, Gorelli (1998) p. 89.

100 Thayer y Novoa (1998) p. 195. Además, sentencia de la Corte de Apelaciones de Santiago de 2 de julio de 1992. RDJ, T. LXXXIX (1992), SEC tercera, p. 149.

101 Véase Román (1992) p. 369; Morato (2011) p. 60; y Rodríguez-Piñero (1988) p. 14.
} 
IRURETa URIarte, Pedro — "La salida intempestiva y la negativa a trabajar: Un supuesto de abandono..."

diente de asistir ${ }^{102}$; cuando se le exigió cumplir tareas adicionales invocando para ello una norma genérica del contrato colectivo ${ }^{103}$; o bien cuando se negó a ejecutar funciones que claramente desbordaban el cargo o función contractualmente pactado ${ }^{104}$. No obstante, también han existido supuestos en que una mirada más amplia del cargo o función -contractualmente pactado- ha significado validar el despido llevado a cabo por el empleador. De esta manera, por ejemplo, la jurisprudencia concluyó que el trabajador "contratado en calidad de maestro panadero-pastelero, que no acepta confeccionar pan de pascua, pretextando que se trata de una labor extraordinaria que debe remunerarse separadamente" incurre en la causal consistente en negativa a trabajar sin causa justificada ${ }^{105}$.

Una interpretación restrictiva de la causal, lleva a concluir que solo el incumplimiento de aquellas funciones pactadas en el contrato puede ser esgrimido como fundamento de la hipótesis extintiva ${ }^{106}$. Una tesis más amplia, por el contrario, plantea algunas dudas sobre figuras complementarias del contrato. Por ejemplo, no hay claridad si la causal permite sancionar la negativa a trabajar en virtud de tareas derivadas del Reglamento Interno. Tampoco existe consenso en lo que respecta a aquellas labores ordenadas por el empleador en virtud del ius variandi ${ }^{107}$. Por último, más de alguna duda genera el hecho de saber si el trabajador está o no obligado a ejecutar una orden relacionada con tareas que si bien ha venido realizando en el tiempo, la misma no estaba consagrada en el contrato.

La primera hipótesis no debiera generar mayores inconvenientes, en el entendido que el Reglamento Interno se encuentra incorporado dentro de las obligaciones del contrato de trabajo y forma parte del mismo. Toda orden del empleador, que suponga la

\footnotetext{
102 Véase sentencia de la Corte de Apelaciones de Santiago de 9 de julio de 2012 (Rol N 245-2012).

103 Véase sentencia de la Corte Suprema de 29 de septiembre de 1983, en ThaYer y Rodríguez (1988) p. 332.

104 Véase sentencia de la Corte Suprema de 19 de junio de 1996. RDJ, T. XCIII (1996), SEC tercera, p. 87: “(...) se encuentra acreditado que el actor fue contratado como junior de la demandada, para desempeñar funciones en las oficinas de esta, consistiendo sus labores en el transporte de documentos, depósitos bancarios, pagos de cuentas de la empresa y aseo menor (limpieza de escritorios); y, la labor encomendada el día 10 de octubre de 1995, que el actor se negó a realizar y que motiva el despido, consistió en la limpieza de ventanas de una obra de la empresa; pero tal hecho no constituye una negativa a trabajar sin causa justificada en las faenas convenidas (...)”. En el plano doctrinal, véase además, BAYLOS (1977) p. 262.

105 Véase sentencia de la Corte Suprema de 4 de diciembre de 1985. RDJ, T. LXXXII (1985), SEC tercera, p. 160. Un criterio distinto, sin embargo, siguió la sentencia de la Corte de Apelaciones de Santiago de 22 de julio de 1991. GJ No 133 (1991), p. 112: “5) Que no se discute en autos que el trabajo contractual del actor era el de panadero. Pues bien (...) (se) le mandó hacer dos quintales de pan corriente y un quintal de pan de molde, negándose el trabajador a hacer pan de molde porque no se le pagaba, agregando que cada panadero tenía la tarea de hacer dos quintales de cualquier pan, sea corriente o especial. (...). $6^{\circ}$ ) Que de los testimonios arriba relacionados no aparece que el actor haya abandonado, dejado o desamparado su trabajo de panadero, negándose totalmente a laborar para su empleador”. La misma lógica sostuvo la sentencia de la Corte Suprema de 9 de abril de 1991. RFM No 389 (1991), p. 84, en relación con un jefe de ventas que fue despedido por negarse a trabajar en labores de crédito y cobranza que su empleador le ordenó realizar en una empresa filial. Según la Corte, esas tareas eran ajenas a la labor para la cual fue contratado el trabajador.

106 Un ejemplo de este criterio restrictivo puede observarse en la sentencia de la Corte Suprema de 22 de mayo de 1968. RDJ, T. LXV (1968), SEC tercera, p. 52. En dicha ocasión, la Corte estimó que la causal de terminación del contrato de trabajo que se refiere al abandono de trabajo, no se configura si el trabajador se niega a realizar una determinada labor que posee el carácter de transitoria y accidental.
}

107 Macchiavello (1986) p. 521. 
realización de tareas propias del cargo y función, y cuyo fundamento se encuentre en el Reglamento Interno, debe ser obedecida por el trabajador. Y si no lo cumple, incurre en la causal de la letra b) del artículo $160 \mathrm{~N}^{\circ} 4$ del Código. Así ocurrirá, por ejemplo, cuando el trabajador se niegue a prestar servicios utilizando los medios de protección necesarios e indispensables para el desempeño de la función. Esta sería una forma indirecta de negarse a prestar servicios en los términos que legal o contractualmente deben exigirse. A fin de cuentas, el Reglamento establece obligaciones, sistemas de turnos, normas especiales pertinentes a las diversas clases de faenas, entre otras materias, cuestión que ciertamente se vincula con la obligación de prestar servicios ${ }^{108}$.

El segundo caso planteado tiene un mayor grado de dificultad. Como es sabido, el ius variandi constituye una facultad legalmente reconocida por el ordenamiento jurídico a objeto que el empleador pueda modificar los límites de la prestación de servicios. Se trata de una facultad de modificación que solo se puede ejercer ciñéndose rigurosamente a las condiciones que el propio ordenamiento jurídico y el contrato señalan, sin que sea lícito para el acreedor de trabajo disponer de esta atribución en forma antojadiza o incondicionada ${ }^{109}$. Y ante el ejercicio de ese derecho, el trabajador se encuentra obligado a obedecer la orden o decisión del empleador que solo podrá rechazar cuando el ejercicio de este supuesto derecho sea ilegal.

En esta perspectiva, el artículo 12 CT faculta al empleador para alterar la naturaleza de los servicios, a condición de que se trate de labores similares, siempre y cuando no provoque menoscabo al trabajador. Una lógica similar siguen los demás supuestos de ius variandi que establece el Código ${ }^{110}$. Las facultades de variación permiten que, en principio, el empleador pueda alterar unilateralmente los límites de la prestación de servicios en relación con modificaciones no sustanciales. En los demás casos, una modificación sustancial requiere de acuerdo entre las partes de conformidad con lo establecido en el artículo $5^{\circ}$ del Código. De esta manera, para evaluar la factibilidad de un cambio unilateral por parte del empleador resulta preciso que la negativa del trabajador se verifique en aquellos casos en que se encuentra contractualmente obligado a prestar servicios. De allí que la jurisprudencia haya estimado que no puede reputarse injustificada la negativa del trabajador a cumplir la orden cuando ella se impartió fuera de su jornada ${ }^{111}$.

Con todo, la propia jurisprudencia ha considerado que la negativa a trabajar en casos de ius variandi no puede amparar la autotutela del trabajador. Si en estos casos, efectivamente, el trabajador cuenta con recursos jurídicos especiales para oponerse a la orden del empleador (v. gr., el procedimiento de reclamo), y no hace uso de los mismos, sino que por el contrario optó por la autotutela, entonces ese proceder constituye una "actitud de

\footnotetext{
108 Artículo 154 CT.

109 Véase Valdés (1974) pp. 8 y ss. Véase también Pérez (1986) p. 105; y Bejarano (2010) p. 649 y ss.

110 Entre otros los artículos 29 CT, 89 CT y 101 CT.

111 Sentencia de la Corte de Apelaciones de Puerto Montt de 4 de julio de 2011 (Rol No 44-2011). Criterios similares pueden observarse en algunos dictámenes de la Dirección del Trabajo, en el sentido que el empleador no puede arrogarse un poder sin contrapesos para decidir libremente qué función desempeña el trabajador, o en qué período de tiempo debe ejecutar sus labores. Sobre el particular, véase, entre otros dictámenes, No 47932014, No 4353-2014, No 4012-082, 3363-103 y 5586-331.
} 
autotutela y de indisciplina laboral, proscrita en nuestro ordenamiento jurídico" ${ }^{112}$. Nuevamente, es una aplicación del tradicional solve et repete, y que en la práctica lleva a exigir que el trabajador primero cumpla la orden y después reclame. Con todo, en estos casos habrá que aceptar que si en el ejercicio del ius variandi se respetan los límites y condiciones legalmente impuestas, entonces el trabajador debe entenderse obligado a cumplir la orden respectiva ${ }^{113}$.

En cuanto a la legitimidad de desobedecer órdenes relacionadas con tareas que se hayan ido asumiendo en el tiempo, aun cuando eran extrañas al pacto inicialmente celebrado, lo cierto es que existe una mirada más bien restrictiva de esta alternativa. En general, la doctrina tiende a justificar la desobediencia de este tipo de funciones ya que en la práctica supondrían ampliar en los hechos el poder de dirección del empleador, al margen por cierto de lo que indica el contrato ${ }^{114}$.

\section{CONCLUSIONES}

El Código del Trabajo sanciona supuestos de abandono que, sin constituir renuncia al empleo, dejan al descubierto incumplimientos contractuales que de acuerdo a la gravedad permiten extinguir el contrato de trabajo. Para configurar la falta por abandono, no resulta necesario un requerimiento previo del empleador a objeto que el trabajador ponga fin a su conducta. En el fondo, el abandono supone infringir los deberes de obediencia como contrapartida del poder de dirección del empleador.

El abandono por incumplimiento exige que la actitud del trabajador carezca de justificación. En la práctica jurisprudencial, la evaluación de una causa justificante ha estado circunscrita a la denominada teoría de la gradualidad. De esta forma, nuestros tribunales laborales tienden a concluir que la justificación del abandono debe ser apreciada de acuerdo a las circunstancias particulares de cada caso, prevaleciendo siempre una mirada de racionalidad que permita explicar el comportamiento del trabajador.

La figura de la salida intempestiva (a que se refiere el artículo $160 \mathrm{~N}^{\circ} 4$ ), implica un partir de un lugar a otro de forma tal que se produce una interrupción indebida de las labores contractualmente asumidas. Esta salida está limitada por un requisito locativo (el sitio de la faena) y otro temporal (durante las horas de trabajo). Estos requisitos reafirman el carácter contractual de la infracción, y deja de lado cualquier pretensión de reproche sobre conductas extralaborales.

En cuanto a la negativa injustificada a trabajar (también regulada en el artículo $160 \mathrm{~N}^{\circ} 4$ ), ella representa un caso clásico de desobediencia e indisciplina. De esta manera, la conducta prohibida se refiere tanto a infracciones derivadas del no cumplimiento del

\footnotetext{
112 Véase sentencia de la Corte Suprema de 23 de agosto de 2005 (Rol N²121-2004).

113 García (1979) p. 894. Por el contrario, "frente a un ius variandi abusivo o ilícito, al trabajador corresponde un legítimo ius resistentaie” véase, VALDÉs (1974) p. 46. En este mismo sentido, véase además, BAYLOS (1997) pp. 262 y 263.

114 Véase Román (1992) p. 365: "Resulta absolutamente irónico que funciones que el trabajador asume en un momento determinado en virtud del principio de buena fe o por miedo a un despido, se entiendan integradas en su prestación”. En relación con este aspecto, además RodríGuEz (1974) p. 273.
} 
contrato laboral así como de órdenes precisas que imparta el empleador dentro del ejercicio regular de su poder de dirección. Con todo, la jurisprudencia ha estado conteste en el hecho de que la negativa injustificada requiere de una actitud intencionada, consciente y deliberada, además de grave, por parte del trabajador.

Los dos casos de abandono que sanciona el artículo $160 \mathrm{~N}^{\circ} 4 \mathrm{CT}$, han puesto en discusión el alcance del principio solve et repete (obedece y después reclama). Este principio, históricamente aplicado por la jurisprudencia, partía de la base que el trabajador no puede atribuirse para sí la calificación del fundamento del abandono, toda vez que la desobediencia legítima solo sería una herramienta subsidiaria a la correspondiente reclamación administrativa o judicial.

No obstante, en los últimos años, el criterio jurisprudencial se ha ido abriendo paso a supuestos genéricos de desobediencia justa, obligando a centrar la orden del empleador dentro del ejercicio regular del poder de dirección. Por ello, el principio del solve et repete ha tenido que evolucionar hacia un delicado equilibrio que armonice la presunción de legitimidad de una orden empleadora con el correspondiente ius resistentiae.

\section{BIBLIOGRAFÍA CITADA}

Aguilera IzQuierdo, Raquel (1997): Las causas del despido disciplinario y su valoración por la jurisprudencia (Pamplona, Editorial Aranzadi).

Albiol Montesinos, Ignacio (1987): "Un supuesto particular de ius resistentiae: negativa a cumplir una sanción de traslado en tanto no sea confirmada judicialmente. Posible relación con el derecho a la tutela judicial efectiva”, Poder Judicial, No 5: pp. 151-158.

Alonso Olea, Manuel (1957): El despido. Un estudio de la extinción del contrato de trabajo por voluntad del empresario (Madrid, Instituto de Estudios Políticos).

Álvarez Martínez, José César (1995): "Del permiso laboral para el cumplimiento de un deber inexcusable de carácter público y personal. Comentario del apartado d) del número 3 del artículo 37 del E.T.”, Tribunal Social, N 65: pp. 45-51.

Arias Domínguez, Ángel (2013): Absentismo laboral (Pamplona, Editorial Civitas/Thomson Reuters).

Baylos Grau, Antonio (2002): "La autotutela del trabajador frente a las extralimitaciones del poder de dirección del empresario", en Cabezas Pereiro, Jaime, Lousada ArocheNA, José Fernando, y Movilla García, Matías (coord.), Las limitaciones de los poderes empresariales y las responsabilidades por su utilización ilegítima (Granada, Editorial Comares) pp. 33-52.

Baylos Grau, Antonio (1977): "La negativa a realizar trabajos de categoría inferior, causa justa de despido. La negación de un derecho de resistencia del trabajador frente al poder de variación empresarial", Revista de Política Social, № 114: pp.262269.

Bejarano Hernández, Andrés (2010): "Irrenunciabilidad del poder de dirección del empresario y límites convencionales al mismo", Revista Española de Derecho del Trabajo, № 147: pp. 639-659. 
IRURETA URIARTE, Pedro — "La salida intempestiva y la negativa a trabajar: Un supuesto de abandono..."

Bidon Y Vigil De Quiñones, José Ignacio (2001): El despido disciplinario y sus causas (Editorial Comares, Granada).

Briones GonzÁlez, Carmen (1995): La extinción del contrato de trabajo por causas objetivas (Madrid, Centro de Publicaciones Ministerio de Trabajo y Seguridad Social).

Cámara Botia, Alberto (1996): "El derecho del trabajador a interrumpir el trabajo en caso de riesgo grave e inminente para su vida o salud: un apunte sobre sus precedentes normativos y jurisprudenciales", Aranzadi Social, vol. I: pp. 2759-2770.

Camps Ruiz, Luis Miguel (1981): "La huelga como causa de despido (una aproximación al tema después de la sentencia del Tribunal Constitucional de 8 de abril de 1981)", Revista de Trabajo, Nos 61-62: pp. 13-34.

Cos EgEA, Manrique (2010): "Los trabajadores especialmente sensibles a determinados riesgos en la doctrina judicial”, Aranzadi Social, N 12: pp. 79-106.

Davis, Pedro R. (s/f): Terminación del contrato de trabajo (Santiago, Editorial Bibliográfica Chilena).

Delgado Ucelay, Isabel (1992): "Faltas repetidas e injustificadas de asistencia al trabajo", en AA.VV., Estudios sobre el despido disciplinario (Madrid, Acarl, segunda edición) pp. 121-140.

Despax, Michel (1982): "L'évolution du rapport de subordination", Droit Social, No 1: pp. 11-19.

Dieguez Cuervo, Gonzalo (1971): "Sobre la obediencia del trabajador", Revista de Política Social, No 91: pp. 77-99.

Durán López, Federico (2013): “El despido por participación en huelga ilegal”, Relaciones Laborales, No 2013: pp. 21-31.

Fernández GonzÁlez, Víctor (1981): “Aspectos penales de la obediencia debida”, Revista de Política Social, No 131: pp. 53-60.

Fernández Madrid, Juan Carlos (1990): Tratado Práctico de Derecho del Trabajo, Tomo II (Editorial La Ley, Buenos Aires).

Ferrante, Vincenzo (2001): “Controllo sui lavoratori, difesa della loro dignitá e Potere disciplinare a quarant'anni dallo Statuto", Rivista Italiana di Diritto del Lavoro, No 1: pp. 73-93.

Gárate Castro, Javier (1981): "Las faltas de asistencia o puntualidad como incumplimiento contractual justificativo de despido disciplinario", Revista de Política Social, No 129: pp. 201-217.

García Blasco, Juan, y González Labrada, Manuel (1996): "El derecho del trabajador a interrumpir su actividad y abandonar el lugar de trabajo en situaciones de riesgo grave e inminente”, Aranzadi Social, vol. I: pp. 2771-2786.

García Fernández, Manuel (1980): "El rendimiento debido en la relación de trabajo": Revista Española de Derecho del Trabajo, No 3: pp. 361-394.

García Ninet, José-Ignacio (1979): "El deber de obediencia en el contrato de trabajo (notas para un estudio)", Revista de Derecho Privado, No 10: pp. 859-919.

García-Núñez Serrano, Francisca (2005): "La indisciplina o desobediencia en el trabajo como causa del despido disciplinario [art. 54.2 b) ET]”, Actualidad Laboral, No 15: pp. 1818-1830. 
Garrigues Giménez, Amparo (2000a): “Obediencia debida y desobediencia del trabajador: su tratamiento en la última jurisprudencia”, Tribuna Social, No 120: pp. 39-54.

Garrigues Giménez, Amparo (2000b): "Deber de obediencia y despido por desobediencia”, en García Ninet, J. I. (director), Cuadernos de Jurisprudencia Laboral y de Seguridad Social, No 12 (Madrid, CISS) pp. 11-37.

GHerA, Edoardo (2006): "Subordinazione, Statuto Protettivo e Qualificazione del Rapporto di Lavoro", Giornale di Diritto del Lavoro e di Relazioni Industriali, N 109 , anno XXVIII: pp. 1-37.

Gil Plana, Juan (2005): "Las faltas repetidas e injustificadas de asistencia o puntualidad al trabajo como causa de extinción de los contratos", Actualidad Laboral, No 12: pp. $1456-1467$.

Gómez Abelleira, Francisco Javier (2009): La causalidad del despido disciplinario (Pamplona, Editorial Civitas/Thomson Reuters).

González Ortega, Santiago (1983): Absentismo y despido del trabajador (Pamplona, Editorial Aranzadi).

Gorelli Hernández, Juan (1998): “Deber de obediencia y despido por desobediencia”, en Revista Española de Derecho del Trabajo, No 87: pp. 73-110.

Luque Parra, Manuel (1999): Los límites jurídicos de los poderes empresariales en la relación laboral (Barcelona, J. M. Bosch Editor).

Macchiavello Cuneo, Guido (1986): Derecho del Trabajo, Tomo I (Santiago, Fondo de Cultura Económica).

Martínez EMPERAdor, Rafael (1992): "La participación en huelga como causa de despido disciplinario: marco regulador”, en AA.VV., Estudios sobre el despido disciplinario (Madrid, Acarl, segunda edición) pp. 325-361.

Martínez Girón, Jesús (1988): El despido en el Derecho de los Estados Unidos (Editorial Civitas, Madrid).

Mendez Holgado, José (1999): "Criterios jurisprudenciales sobre la desobediencia e indisciplina y las ofensas como causa de despido disciplinario", Revista Española de Derecho del Trabajo, No 94: pp. 297-308.

Montoya Melgar, Alfredo (2011): "Libertad de empresa y poder de dirección del empresario en las RL", en SÁNCHEZ, Carmen (coord.), Libertad de empresa y poder de dirección del empresario en las Relaciones Laborales. Estudios ofrecidos al profesor Alfredo Montoya Melgar (Pamplona, Aranzadi/Thomson Reuters) pp. 27-48.

Montoya Melgar, Alfredo (2008): Derecho del Trabajo (Madrid, Editorial Tecnos, vigésima novena edición).

Montoya Melgar, Alfredo (2000): "El poder de dirección del empresario (en torno al artículo 20)”, en VV.AA., El Estatuto de los Trabajadores. Veinte años después (Madrid, Editorial Civitas) pp. 575-596.

Montoya Melgar, Alfredo (1985): “Dirección de la Actividad Laboral”, en Borrajo Dacruz, Efrén (dir.), Comentarios a las Leyes Laborales. El Estatuto de los Trabajadores, Tomo V (Madrid, Edersa).

Montoya Melgar, Alfredo (1965): El poder de dirección del empresario (Madrid, Instituto de Estudios Políticos). 
Morato García, Rosa María (2011): Derecho de resistencia y ejercicio irregular del poder de dirección (Granada, Editorial Comares).

Muñoz Campos, José (1986), "La desobediencia y la indisciplina, causas de despido en la jurisprudencia de la Sala de lo Social", Revista Española de Derecho del Trabajo, No 26: pp. 277-302.

Ortiz Lallana, Ma. Carmen (2000): "Causas, forma y efectos del despido disciplinario" (en torno a los artículos 54 y 55)”, en VV.AA., El Estatuto de los Trabajadores. Veinte años después (Madrid, Editorial Civitas) pp. 1113-1160.

Palomeque López, Manuel Carlos (1992): "La indisciplina o desobediencia en el trabajo", en AA.VV., Estudios sobre el despido disciplinario (Madrid, Acarl, segunda edición) pp. 141-160.

Pedrajas Moreno, Abdón (1990): "Traslado y obediencia debida del trabajador: criterios jurisprudenciales", Actualidad Laboral, No 33: pp. 381-399.

Pedrajas Moreno, Abdón, y Sala Franco, Tomás (2009): Ausencias al trabajo y absentismo (Valencia, Editorial Tirant lo Blanch).

PÉrez del Río, Teresa (1986): "La regularidad del ejercicio del poder empresarial y la obediencia debida: comentario a la sentencia del Tribunal Supremo de 7-III-1986", Temas Laborales, N 8: pp. 183-206.

Rodríguez SaÑudo, Fermín (1974): "Desobediencia a órdenes injustas del empresario: sometimiento del trabajador y disciplina en la empresa”, Revista de Política Social, N $^{\circ} 104$ : pp. 271-275.

Rodríguez-Piñero y Bravo-Ferrer, Miguel (1988), "Obediencia debida y desobediencia justificada", Relaciones Laborales, $\mathrm{N}^{\circ}$ 2: p. 1-11.

Rojas Rivero, Gloria Pilar (2014): "La extinción del contrato de trabajo por abandono", en Monereo Pérez, José Luis, (dir.) Modalidades de extinción del contrato de trabajo: análisis de su régimen jurídico (Granada, Editorial Comares) pp. 355-370.

Román de la Torre, María Dolores (1992): Poder de dirección y contrato de trabajo (Valladolid, Ediciones Grapheus).

Sagardoy Bengoechea, Juan Antonio (1968): "La disminución del rendimiento como causa de despido", Revista de la Facultad de Derecho de la Universidad de Madrid, Vol. XII, No 33: pp. 415-428.

Sala Franco, Tomás (2001): El régimen jurídico de las ausencias al trabajo (Valencia, Editorial Tirant lo Blanch).

SAVATIER, Jean (2003): "Le retrait de situation dangereuse fondé sur l'insécurité du travail en zone urbaine”, Droit Social, No 9/10: pp. 805-807.

Sempere Navarro, Antonio-Vicente (2001): "La imposibilidad de trabajar y el artículo 30 ET”, Aranzadi Social, No 9: pp. 117-125.

SuÁrez GonzÁlez, Fernando (1969): "La indisciplina como causa de despido", en VV.AA., Dieciséis lecciones sobre causas de despido (Madrid, Servicio de Publicaciones e Intercambio Facultad de Derecho, Universidad de Madrid): pp. 85-90.

Thayer Arteaga, William, y Novoa Fuenzalida, Patricio (1998): Manual de Derecho del Trabajo, Tomo III (Santiago, Editorial Jurídica de Chile, tercera edición). 
Thayer Arteaga, William, y Rodríguez Alvarado, Antonio (1988): Código del Trabajo y Legislación Social (Santiago, Editorial Jurídica de Chile/Editorial Jurídica Ediar ConoSur Ltda.).

VALDÉs DAL-RÉ, Fernando (1974): "La ruptura del principio de correspondencia funcióncategoría por ejercicio del ius variandi”, en Revista de Política Social, No 103: pp. 5-49.

Walker Errázuriz, Francisco (1990): Terminación del contrato de trabajo (Santiago, Editorial Cepet).

\section{NORMAS CITADAS}

Constitución Política de la República de chile (24/10/1980).

Decreto con Fuerza de Ley No 1 (27/3/2003), Código del Trabajo

LEY $N^{\circ} 16.455(6 / 4 / 1966)$, Sobre normas para la terminación del contrato de trabajo

Decreto con Fuerza de Ley Nº 178 (13/5/1931), Código del Trabajo de 1931

LEY N 4.053 (29/9/1924), Sobre contrato de trabajo.

\section{JURISPRUDENCIA JUDICIAL CITADA}

VÁsuez DuRán con Modas EVITA S.A. (2010): Corte Suprema 28 de julio de 2010 (Recurso de Casación en el Fondo), Rol No 2628-2010, RFM No 554 (2010), p. 513.

Álvarez Fuentes con Frutícola AgriChile S.A. (2009): Corte Suprema 18 de marzo de 2009 (Recurso de casación en el fondo), Rol No 7977-2008, en www.poderjudicial.cl.

Peña Castillo con Evaluadora de CRÉditos Lesel Ltda. (2008): Corte Suprema 4 de noviembre de 2008 (Recurso de casación en el fondo), Rol N 5813-2008, en www.poderjudicial.cl

Crisosto Navarro y Otros con Inmobiliaria e InVERsiones Los Alerces del ARrayÁn Ltda. (2008): Corte Suprema 8 de abril de 2008 (Recurso de casación en el fondo), Rol N ${ }^{\circ}$ 588-2008, en www.poderjudicial.cl

Lizama Farías y Otros con Hasbún Hasbún, Carlos (2006): Corte Suprema 26 de enero de 2006 (Recurso de casación en la forma), Rol N 4413-2004, en www.poderjudicial.cl

GALVEZ IBARRA CON SERVICIO IDEAL LIMITADA (2006): Corte Suprema 24 de enero de 2006 (Recurso de Casación en el Fondo), Sin Rol, RDJ, T. CIII (2006), SEC tercera, p. 225.

lozano Donaire con Comercial Automotriz Antonio Garrido y Compañ́a Limitada (2005): Corte Suprema 23 de agosto de 2005 (Recurso de casación en el fondo), Rol Nº 2121-2004), en www.poderjudicial.cl

Cácamo Mansilla y otros con Pesca Chile S.A. (2000): Corte Suprema 31 de julio de 2000 (Recurso de casación en el fondo), Sin Rol, RDJ, T. XCVII (2000), SEC tercera, pp. 141 y siguientes.

Velásquez Durán con Indusmetal Construcciones LtdDa. (1996): Corte Suprema 19 de junio de 1996 (Recurso de casación en el fondo), Sin Rol, RDJ, T. XCIII (1996), SEC tercera, p. 87. 
IRURETA URIARTE, Pedro — "La salida intempestiva y la negativa a trabajar: Un supuesto de abandono..."

Aguillon Curguan con Sociedad Gratal Hermanas y Cía. LtdaA. (1992): Corte Suprema 13 de agosto de 1992 (Recurso de queja), Rol No 5.600, RFM No 405 (1992), p. 569.

Sociedad Técnica y Comercial Soquina Ltda. contra CAP de Santiago (1991): Corte Suprema 9 de abril de 1991 (Recurso de queja) Rol No 2292, RFM No 389 (1991), p. 84.

Domínguez GarRido contra CAP DE SANTiago (1990): Corte Suprema 4 de abril de 1990 (Recurso de queja), Rol No 652-89, RDJ, T. LXXXVII (1990), SEC tercera, p. 28.

Manufacturas PRotec Ltda. contra CAP de TalCa (1986): Corte Suprema 2 de abril de 1986 (Recurso de queja), Rol No 2080, RDJ, T. LXXXIII (1986), SEC tercera, p. 11.

Sociedad Comercial y Pastelería El Molino Ltda. contra CaP de Santiago (1985): Corte Suprema 4 de diciembre de 1985 (Recurso de queja), Rol N 1223, RDJ, T. LXXXII (1985), SEC tercera, p. 160.

GonzAlez con Confecciones García LtdDA. (1983): Corte Suprema 29 de septiembre de 1983 (en Thayer Arteaga, William, y Rodríguez Alvarado, Antonio, 1988, Código del Trabajo y Legislación Social, Santiago, Editorial Jurídica de Chile/Ediar ConoSur Ltda., p. 332.

Bravo Vera contra CAP de SAntiago (1982): Corte Suprema 7 de enero de 1982 (Recurso de queja), Rol No 604, RDJ, T. LXXIX (1982), SEC tercera, p. 1.

Tamayo Henríquez contra Corte del TRabajo de Valparaíso (1980): Corte Suprema 8 de mayo de 1980 (Recurso de queja), Sin Rol, RDJ, T. LXXVII (1980), SEC tercera, p. 20.

Películas Mexicanas S.A. contra Corte del Trabajo de Santiago (1968): Corte Suprema 4 de octubre de 1968 (Recurso de queja), Sin Rol, RDJ, T. LXV (1968), SEC tercera, p. 160.

Marco Chilena Ltda. contra Corte del Trabajo de Iquique (1968): Corte Suprema 22 de mayo de 1968 (Recurso de queja), Rol No 1345, RDJ, T. LXV (1968), SEC tercera, p. 52.

Sociedad Anónima Heiremans de Construcciones Metalicas SOCOMETAL contra Corte del TRabajo de SANTiago (1961): Corte Suprema 16 de octubre de 1961 (Recurso de queja), Sin Rol, RDJ, T. LVIII (1961), SEC tercera, p. 85.

Caja de Previsión de Empleados Particulares contra Corte del trabajo de Valparaíso (1961): Corte Suprema 14 de diciembre de 1961 (Recurso de queja), Rol No 10.567, RFM No 37 (1961), p. 276.

Shell-Mex Chile Ltda. Contra Corte de Santiago (1936): Corte Suprema 6 de agosto de 1936 (Recurso de queja), Sin Rol, RDJ, T. XXXIII (1936), SEC primera, p. 418.

Prieto contra Corte de VAlparaíso (1934): Corte Suprema 12 de enero de 1934 (Recurso de queja), Sin Rol, RDJ, T. XXXI (1934), SEC primera, p. 223.

SANDOVAL CON OLGUÍN (2015): Corte de apelaciones de Antofagasta 16 de febrero de 2015 (Recurso de Nulidad), Rol N 197-2014, en www.poderjudicial.cl

Jara Con Corporación PrínCipe de Gales (2014): Corte de apelaciones de Santiago 20 de mayo de 2014 (Recurso de Nulidad), Rol N 1906-2013, en www.poderjudicial.cl

Chávez con PRosegur Regiones Limitada y Otro (2014): Corte de Apelaciones de Chillán 8 de abril de 2014 (Recurso de Nulidad), Rol N²1-2014, en www.poderjudicial.cl 
Lagos con TRANSPORTES Ricardo LEIVA S.A. (2010): Corte de apelaciones de Rancagua 5 de agosto de 2010 (Recurso de Nulidad), Rol No 95-2010, en www.poderjudicial.cl.

Zúñiga con Compass Catering y SeRvicios hile LtdDA. (2013): Corte de apelaciones de Puerto Montt 13 de diciembre de 2013 (Recurso de Nulidad), Rol N 144-2013, en www. poderjudicial.cl

Crisóstomo con Sociedad Metalmecánica Parada López Ltda. (2013): Corte de apelaciones de Chillán 12 de diciembre de 2013 (Recurso de Nulidad), Rol N 109-2013, en www.poderjudicial.cl

Galvez Gálvez y Otros con Sociedad de Transportes Cancino y Cía. Ltdda., Coca Cola EMBONOR S.A. (2013): Corte de apelaciones de Rancagua 4 de noviembre de 2013 (Recurso de Nulidad), Rol No 128-2013, en www.poderjudicial.cl.

Buenante Flores con Transportes Alberto Díaz Parraguez EIRL (2013): corte de apelaciones de Concepción 1 de octubre de 2013 (Recurso de Nulidad), Rol N²25-2013, en www.poderjudicial.cl

Sociedad de EduCACión Alihuen S.A. con Arcos (2013): Corte de apelaciones de Puerto Montt 9 de septiembre de 2013 (Recurso de Nulidad), Rol N 99-2013, en www.poderjudicial.cl

Avalos Rivera CON PRE UNIC S.A. (2013): Corte de Apelaciones de La Serena 2 de septiembre de 2013 (Recurso de Nulidad), Rol N 85-2013, en www.poderjudicial.cl.

Agroindustrial del Norte S.A. con Mansilla Peralta (2012): Corte de Apelaciones de La Serena 7 de diciembre de 2012 (Recurso de Nulidad), Rol No 95-2012, en www.poderjudicial.cl

MANSILla con GSL COMERCIAL EIRL (2012): Corte de apelaciones de Temuco 29 de octubre de 2012 (Recurso de Nulidad), Rol N²11-2012, en www.poderjudicial.cl.

Muñoz con Logística Providencia Ltda. (2012): Corte de apelaciones de Santiago 7 de septiembre de 2012 (Recurso de Nulidad), Rol N 594-2012, en www.poderjudicial.cl

PIÑONES CON REDBUS URBANO S.A. (2012): Corte de apelaciones de Santiago 9 de julio de 2012 (Recurso de Nulidad), Rol No 245-2012, en www.poderjudicial.cl

Durán con Empresa de SerVicios Himce Limitada (2011): Corte de apelaciones de Concepción 16 de agosto de 2011 (Recurso de Nulidad), Rol N²05-2011, en www.poderjudicial.cl

VARGAS GALLARDo CON FRASAL S.A. (2011): Corte de apelaciones de Puerto Montt 4 de julio de 2011 (Recurso de apelación), Rol N 44-2011, en www.poderjudicial.cl

Express de SANTiago UNo S.A. con LorCa (2011): Corte de apelaciones de Santiago $21 \mathrm{de}$ marzo de 2011 (Recurso de Nulidad), Rol No 1500-2010, en www.poderjudicial.cl

Villaseca Montesinos con Industria de Plastico Plaserco Ltda. (2009): Corte de apelaciones de San Miguel 21 de diciembre de 2009 (Recurso de apelación), Rol № 4822009, en www.poderjudicial.cl

GonZALEZ SEQUEIDA CON EMPRESA EASY S.A. (2007): Corte de apelaciones de Rancagua 19 de octubre de 2007 (recurso de Apelación), Rol No 200-2007, en www.poderjudicial.cl

Bustamante Velásquez con CMS TeCnología S.A. (2005): Corte de apelaciones de Antofagasta 3 de agosto de 2005 (Recurso de apelación), Rol N 115-2005, en www.poderjudicial.cl 
Medina Arzola con Forestal Comaco S.A. (2002): Corte de apelaciones de Concepción 6 de septiembre de 2002 (Recurso de Apelación), Rol No 4082-2001. GJ No 267 (2002), p. 191.

Corte de apelaciones de San Miguelde 13 de marzo de 1997, Rol No 282-1996 (en Repertorio de Legislación y Jurisprudencia Chilenas. Código del Trabajo y Leyes Complementarias, T. I, 2002, Santiago, Editorial Jurídica de Chile, p. 57).

Pont Chavez con Televisión Nacional de Chile (1995): Corte de apelaciones de Santiago 19 de junio de 1995 (Recurso de Casación en el Fondo), Rol No 32.341, RFM No 453 (1996), p. 1783.

Gonzalez Bustamante con TRANSportes LAS Condes Vitacura (1994): Corte de apelaciones de Santiago de 11 de noviembre de 1994 (Recurso de Apelación), Rol No 2709-94. RDJ, T. XCI (1994), SEC tercera, p. 271.

Cortés VARGas con TeXtIL CAPITOL S.A. (1992): Corte de apelaciones de Santiago 2 de julio de 1992 (Recurso de apelación), Rol No 897-92, RDJ, T. LXXXIX (1992), SEC tercera, p. 149.

Muñoz con Ganadera Sta. Raquel LtdA. (1991): Corte de Apelaciones de Talca 1 de agosto de 1991 (Recurso de Apelación), Rol N 45.936, GJ No 134 (1991), pp. 144-145.

Huatquiman Pañian con Suc. Felicindo Rodríguez D. (1991): Corte de apelaciones de Santiago 22 de julio de 1991 (Recurso de Apelación), Rol N 1149-91, GJ No 133 (1991), pp. 112-113.

Corte de Apelaciones Presidente Aguirre Cerda de 27 de septiembre de 1984, Rol No 44384 (en Thayer Arteaga, William, y Rodríguez Alvarado, Antonio, Código del Trabajo y Legislación Social, Editorial Jurídica de Chile/Ediar Cono-Sur Ltda., Santiago 1988, p. 333).

Corte de Apelaciones Presidente Aguirre Cerda de 28 de marzo de 1984, Rol No 84-84 (en Thayer Arteaga, William, y Rodríguez Alvarado, Antonio, Código del Trabajo y Legislación Social, Editorial Jurídica de Chile/Ediar Cono-Sur Ltda., Santiago 1988, p. 333).

\section{JURISPRUDENCIA ADMINISTRATIVA CITADA}

Dictamen No 4793-2014, de 2 de diciembre de 2014, de la Dirección del Trabajo, disponible en www.dt.gob.cl

Dictamen No 4353-2014, de 6 de noviembre de 2014, de la Dirección del Trabajo, disponible en www.dt.gob.cl

Dictamen No 4012-082, de 12 de octubre de 2011, de la Dirección del Trabajo, disponible en www.dt.gob.cl

Dictamen No 3363-103, de 20 de agosto de 2003, de la Dirección del Trabajo, disponible en www.dt.gob.cl

Dictamen No 5586-331, de 11 de noviembre de 1999, de la Dirección del Trabajo, disponible en www.dt.gob.cl 